\title{
Energy sufficiency policy for residential electricity use and per-capita dwelling size
}

\author{
Stefan Thomas $\mathbb{D} \cdot$ Johannes Thema • \\ Lars-Arvid Brischke • Leon Leuser • Michael Kopatz • \\ Meike Spitzner
}

Received: 17 November 2017 / Accepted: 20 August 2018 / Published online: 14 November 2018

(C) The Author(s) 2018

\begin{abstract}
Energy sufficiency has recently gained increasing attention as a way to limit and reduce total energy consumption of households and overall. This paper presents both the partly new methods and the results of a comprehensive analysis of a micro- and meso-level energy sufficiency policy package to make electricity use in the home more sufficient and reduce at least the growth in per-capita dwelling size. The objective is to find out how policy can support households and their members, as individuals or as caregivers, but also manufacturers and local authorities in practicing energy sufficiency. This analysis needed an adapted and partly new set of methods we developed. Energy sufficiency does not only face barriers like energy efficiency, but also potential restrictions for certain household members or characteristics, and sometimes, preconditions have to be met to make more energysufficient routines and practices possible. All of this was analysed in detail to derive recommendations for which policy instruments need to be combined to an effective policy package for energy sufficiency. Energy
\end{abstract}

S. Thomas $(\bowtie) \cdot J$. Thema $\cdot$ M. Kopatz $\cdot$ M. Spitzner

Wuppertal Institute for Climate, Environment and Energy,

Wuppertal, Germany

e-mail: stefan.thomas@wupperinst.org

J. Thema

e-mail: johannes.thema@wupperinst.org

M. Kopatz

e-mail: michael.kopatz@wupperinst.org efficiency and energy sufficiency should not be seen as opposed to each other but work in the same directionsaving energy. Therefore, some energy sufficiency policy instruments may be the same as for energy efficiency, such as energy pricing policies. Some may simply adapt technology-specific energy efficiency policy instruments. Examples include progressive appliance efficiency standards, standards based on absolute consumption, or providing energy advice. However, sufficiency may also require new policy approaches. They may range from promotion of completely different services for food and clothes cleaning, to instruments for limiting average dwelling floor area per person, or to a cap-and-trade system for the total electricity sales of a supplier to its customers, instead of an energy efficiency obligation.

Keywords Energy sufficiency · Policy packages · Electricity use $\cdot$ Dwelling size policy $\cdot$ Absolute energy savings $\cdot$ Gender-responsible policy

M. Spitzner

e-mail: meike.spitzner@wupperinst.org

L.-A. Brischke

ifeu-Institute for Energy and Environmental Research,

Heidelberg, Germany

e-mail: lars.brischke@ifeu.de

\section{Leuser}

Europa-Universität Flensburg, Flensburg, Germany

e-mail: leon.leuser@uni-flensburg.de 


\section{Introduction}

In the last four decades, energy efficiency increased significantly in OECD countries (International Energy Agency (IEA) 2016). However, only during the most recent years, total energy consumption started to decrease a little in some countries including Germany and much more slowly than energy efficiency potentials and multiple benefits (IEA 2014) would suggest (Intergovernmental Panel on Climate Change (IPCC) 2014). Sufficiency (e.g. Sachs 1993; Princen 2005) and particularly energy sufficiency (e.g. Wilhite and Norgard 2003; Darby 2007; Calwell 2010; Pfäffli 2012) have therefore gained new attention as a way to limit and eventually reduce total energy consumption of a household or a country overall. As often with new concepts, not even the definition of 'energy sufficiency' is clear in scientific literature (Darby 2007): it could either be seen as an outcome, i.e. as a status of energy use that both provides a 'sufficient' level of utility or services from energy, while respecting the limits of environmentally safe operating space (Rockström et al. 2009), either at the level of the individual or the whole society. Or it could concern the changes in daily routines and practices that bring us closer to such a status. This paper is about the latter, i.e. about energy sufficiency actions, and how policy could support these.

The need to support sufficiency, and more concretely energy sufficiency, with policy has also been examined more recently (Lorek and Fuchs 2013; Schneidewind and Zahrnt 2014; Bertoldi 2017; Toulouse et al. 2017; Spengler 2018). However, we are not aware of any comprehensive and structured analysis of energy sufficiency policies particularly addressing electricity consumption in the household. Behaviour and its potential for saving energy as well as policy instruments targeting behaviour have been subject to intensive research (as documented, e.g. in the proceedings of the BEHAVE conferences and the corresponding sessions at aceee and eceee Summer Studies; cf. also Bertoldi 2017). Energy sufficiency (policy) as we understand it goes beyond the individual and its behaviour, as discussed in the following section. This need has increasingly been recognised in the literature on behaviour such as that mentioned above (e.g. Munkacsi and Mahapatra 2017). It is also due to households being the place where the basic social economy of caring, historically attributed or rejected on a gender-specific basis, is located for structural reasons.
Therefore, we implemented a first comprehensive analysis of a micro- and meso-level energy sufficiency policy addressing electricity use in the household as part of a wider project that examined, what energy sufficiency actually means in terms of concrete action: What could households and their members but also manufacturers and local authorities do to make electricity use of households more sufficient? In our understanding, the micro-level is that of the individual, and the meso-level is the household, particularly the care economy (cf. definition in section 2), and its environment, e.g. manufacturers and local authorities. The macro-level would be the wider society and its structures, culture, and the economy, with its trends and drivers towards or against energy sufficiency. While a truly comprehensive policy would need to address these too, this analysis was beyond the scope of our work and hence also of this paper. However, some of the policies presented later, such as energy pricing policies or dwelling floor area limits, may also be seen as addressing selected macro drivers.

This paper presents both the set of methods used and partly newly developed, with an illustrative example, and the results of this energy sufficiency policy analysis.

The objective of the analysis was to find out how policy can support market actors in using the potential types of energy sufficiency actions identified by the wider project. Energy efficiency and energy sufficiency should not be seen as opposed to each other but work in the same direction - saving energy. The ultimate goal is to reduce energy consumption in absolute terms. In Germany for example, the government adopted the target to reduce electricity consumption by $10 \%$ until 2020 and by $25 \%$ until 2050 , compared to the 2008 value (BMWi 2012).

This paper is organised as follows: We begin with a short presentation of our understanding of energy sufficiency at the household level and its environment ('What is energy sufficiency? The general concept'). 'Methods, particularly for policy development' is the first main part of the paper, the methodological part. It presents the seven-step method we developed and used for policy analysis at the level of domains of electricity use in the household. It starts with a short overview presentation of the methodological approach. As both this subject and the necessary methods are so new, we chose to present the methodological details and an illustrative example carried through its steps in an integrated 
way. In 'Defining the scope and potential actions: steps 1 to 3 of the domain-level analysis', we expand on the first three steps of our seven-step approach that deal with how to identify, focus, and analyse options for energy sufficiency action in the household, its environment, and surrounding infrastructure, with some methodological remarks and the brief example. 'Methods for analysis of what could be appropriate energy sufficiency policy packages: steps 4 to $7^{\prime}$ holds the methods for steps 4 to 7 that we developed and used for the development of a micro/meso-level energy sufficiency policy in electricity use domains, with each step again followed by the example. The second main part of the paper, 'Results: the energy sufficiency and efficiency policy package resulting from the analysis', is presenting the results of this analysis for the domainspecific policies ('Instruments supporting energyefficient and sufficient purchase and use of equipment, and other domain-related practices'), as well as results on overarching policies that address percapita dwelling floor area ('Instruments for limiting average dwelling floor area per person') and electricity consumption overall ('Electricity sales caps and trade for suppliers'). All of these policies are finally combined to the resulting integrated energy sufficiency and efficiency policy package ('An integrated energy sufficiency and efficiency policy package for electricity use in the household'). 'Discussion' continues with a discussion of the methods and results, before the paper ends with short conclusions.

\section{What is energy sufficiency? The general concept}

In terms of its objectives, energy sufficiency is a strategy aiming at limiting and reducing the input of technically supplied energy towards a sustainable level. This level is at first to be defined for society as a whole, i.e. as a nation's energy consumption that will adequately contribute to the world staying within the planetary boundaries (Rockström et al. 2009). We do not have space here to expand on what would be adequate at national level, but it is clear that reducing energy consumption will be a key particularly to mitigating climate change (IPCC 2014). Besides a sustainable and decarbonised energy supply (particularly through the use of renewable energies) and energy efficiency, energy sufficiency is, therefore, the third strategy for sustainability in the energy sector. By the definition we adopted (Brischke et al. 2015), energy sufficiency at the household level differs from energy efficiency in one central aspect: Energy efficiency reduces energy input while keeping the utility/ services constant. ${ }^{1}$ With energy sufficiency, energy input is reduced while the utility/technical service changes in quantity or quality. However, the amount of utility/services should still be 'sufficient' for caring and for the individual (cf. below and footnote 1).

Therefore, energy sufficiency i.a. aims at the corresponding changes in energy-relevant consumption, including 'decisions' (see below) with regard to the purchase and use of equipment. However, energy use is deeply embedded in both daily routines and practices and also inextricably woven into the infrastructures and appliances/equipment that define, and are defined by, what people do (Shove 2017) or are allocated to do. Therefore, when analysing energy sufficiency in the household, the object of analysis is not a single energy-using product. Rather, the starting point is an area of basic needs, constituting a domain of needs and wants that transposes to a request for technical services and consequent energy input. Energy sufficiency thus also takes into account fundamental changes of energy-relevant aspects of lifestyles and social practices. Both aspects are linked with changes in the utility aspects of technical appliances (e.g. the cooling capacity of a refrigerator) and changes in further utility aspects of consumption goods and services (Fischer et al. 2016). As the concept requires changes in the utility or technical service from equipment, energy sufficiency is not the sole responsibility of the individual: it needs to take into account the necessary infrastructure and equipment design to enable more energy-sufficient practices, as well as potential restrictions against such practices or changes in utility. In addition, it needs to distinguish between (1) needs required by the care economy and (2) personal

\footnotetext{
${ }^{1}$ Or, as for example, the European Union's Energy Efficiency Directive (2012/27/EU) defines " "energy efficiency" means the ratio of output of performance, service, goods, or energy, to input of energy'. The types of utility, or technical services, from energy as we analyse here are examples for the output in this definition, cf. also the concept of the transmission or transformation chain discussed later in the text. They are thus also equivalent to a part of the definition of 'energy service' in this Directive: " "energy service" means the physical benefit, utility, or good derived from a combination of energy with energyefficient technology or with action, which may include the operations, maintenance, and control necessary to deliver the service, ...”
} 
needs and wants, e.g. for entertainment. ${ }^{2}$ Care economy comprises the actual practices and the systemically careoriented economic rationality of affective and material work (e.g. provision of clean clothes and food) for stilling the (existential) needs of other persons, who as human beings are mentally and physically socially dependent (cf. the immense research on housework, reproduction, and household production at the latest since von Werlhof 1978). It is important to note that in most societies, the care economy is deeply gendered and subordinated to the market-based economy of goods, services, and labour. ${ }^{3}$

In this analysis, we therefore understand energy consumption at the household level as the result of a transposition or transformation chain that starts with (1) basic human needs as discussed in literature (e.g. Skidelsky and Skidelsky 2013; Wilk 2002; Faiers et al. 2007). These are transformed into (2) more concrete needs (both mostly related to housework and caring) and

\footnotetext{
${ }^{2}$ We are well aware that there is ample discussion in the literature on the distinction between needs and wants, whether it is justified at all, and on what could be an appropriate or sufficient level (e.g. Davis et al. 2015; Wilhite and Lutzenhiser 1997; Wilhite 2016). We cannot go into detail here, and we do not wish to enter into defining what could be 'sufficient' (see in main text below). For this analysis, the distinction between needs and wants is important, as the barriers, restrictions, or preconditions for more energy-sufficient practices may be fundamentally different, particularly where one person cares for another member of the household in a domain of basic needs. This will create needs of caring, not personal wants.

${ }^{3}$ Since 1996, it has been controversial to which extent it will be problematic with regard to sustainability and in shaping societal relations to nature (Schultz 1996; von Winterfeld 2011; Spitzner and Buchmüller 2016), if sufficiency policy does not address the macrolevel and market-based production, but only the meso- and the microlevel, and the care economy (Spitzner and Beik 1995). The latter is usually subsumed under 'consumption', even if it accounts for the majority of household activities. This ignores (a) the societal priority of social reproduction in relation to market production and (b) the currently unsustainable societal organisation of caring and is (c) shifting political responsibilities for the environment to the so-called private sphere. This carries both the risks of a 'feminisation of environmental responsibility' and of a shift to those with little structurally adequate societal shaping power (Schultz 1993). The gender-based societal social-ecological-economical 'crisis of the care economy' (Spitzner 1999) is a core debate in non-androcentric environmental research (e.g. Wichterich 2018; Gottschlich et al. 2014; Schultz 1998; Spitzner and Beik 1995) and connected with the current international debate on social reproduction (Fraser 2016). Necessities are seen for removing the subordination of social reproduction under (market) production in policy and economy (Fraser 2016) in combination with a conversion of the societal symbolic order concerning masculinity models (UBA - German Environment Agency 2018), with a transformation of economy and democracy to a rationalised and materialised care economy and caring democracy (Tronto 2013), as well as with reorganising the political and economical responsibilities for caring without gender-biased exploitation and for the benefit of sustainability.
}

wants, which in turn are transformed into (3) the needed/desired reliefs (from caring work) or utility aspects. These are then transformed into (4) the request of a (more or less technical) utility or service that would provide the relief or utility aspect. Finally, energyrelated products (e.g. appliances) or services (5) supply a technical service. This actual technical service may or may not meet or even exceed the level and quality of technical service or utility that has been requested. In Fig. 1, these five basic concepts are presented at the left to centre.

How exactly every step of the chain is taken will depend on many factors: restrictions within the household (e.g. infrastructural, socio-economic, gender-related), external drivers (e.g. externalisation of work from the wage-labour economy into the unpaid care economy and related gender hierarchisation, peer group, and symbolic consumption trends). This is why we do not attempt to define a 'sufficient' level of technical services or dwelling floor area, or even of the underlying needs and wants (on a more general level, cf. e.g. Bachelet 2011). In our view, this should remain at the discretion of households and their members. Instead, we analyse what could be possible changes in the request for technical services, what are barriers or preconditions for their implementation, and how policy could support, or enable at all, their implementation by households and their members but also other actors (e.g. manufacturers, service providers, local authorities). So, although the chain starts from human needs, we are not grounding this analysis in individual choice theories but rather in social and cultural theories (Wilk 2002) and theories of the care economy (cf. references above). We are also aware that there are many more theories on consumer behaviour (e.g. Faiers et al. presenting an overview table of almost 30 different theories), which may all be useful in an even more detailed analysis than we were able to perform. In addition, the social meanings of any kind of energy-related service in the household have a long history and are constantly changing.

Energy may be saved through different kinds of energy sufficiency actions. For the purpose of our analysis, an energy sufficiency action is defined as a change in this transformation chain and the resulting social practices that will save energy, and will not have negative social or environmental side effects, compared to the status quo ante. The change in the transformation chain ultimately corresponds to and operationalises a change in the utility/technical service provided in 


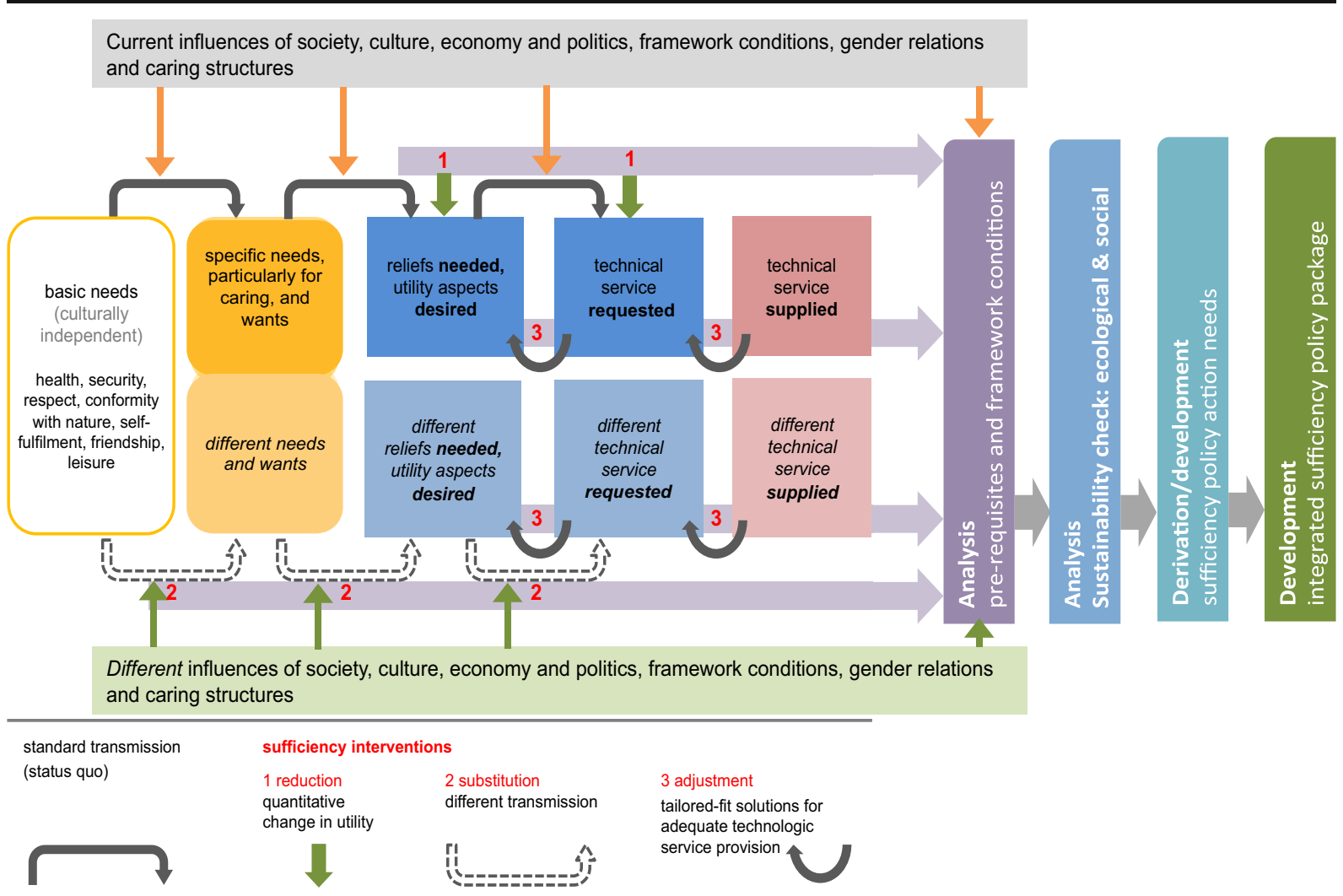

Fig. 1 Standard transformation chain of the determinants of household energy consumption and methodological approach towards developing integrated energy sufficiency policy packages

quantity or quality - the change we defined above as the feature distinguishing energy sufficiency from energy efficiency. Economic cost-effectiveness is not required a priori but subject to analysis. Such energy sufficiency actions can therefore intervene not only along the life cycle of a given product but also at different points of this transformation chain and can follow different approaches (see as well Brischke et al. 2015 and Fig. 1):

1. Reduction (arrows with number 1 in Fig. 1): a quantitative reduction in (a) needed reliefs (e.g. in household work/care economy production, through use of technology) or in utility aspects (e.g. having lighting for reading, or a TV) or in (b) the technical services requested to provide the reliefs or utility (e.g. number and light output of luminaires).

2. Substitution (arrows with number 2 in Fig. 1): a different transformation of basic needs into needed reliefs/utility aspects and consequently of technical services requested. This may include a substitution along the whole transmission chain or only at one of the first three transformation steps. It means a substitution of current practices/routines by different ones, e.g. partly replacing residential clothes washing by external services or by more frequent airing of clothes.

3. Adjustment (arrows with number 3 in Fig. 1): (a) an adjustment of the technical service requested to the actually needed reliefs or desired utility aspects (e.g. appliance size, switching off an appliance when not used, adjusting refrigerator or room temperatures to actual needs, apartment sizes to number of inhabitants) or (b) an adjustment of the technical service supplied by energy-using products to the technical service actually requested by the user, avoiding unnecessary energy waste (e.g. standby functions, internet connectivity).

Sufficiency actions within a domain of needs and wants may take one or more of the three different sufficiency approaches presented above. The steps of transformation, the resulting needs, wants, reliefs, utilities, and technical services and with them, the three sufficiency approaches are also depending a lot on the 
influences of society, culture, social history, economy and politics, general framework conditions, and the cultural order, as well as on gender relations and the structures of the care economy. These influences provide the framework for sufficiency actions, within which households, caregivers (i.e. the person(s) in charge of the care economy in the household), and individuals act in a principally rational way (cf. also Shove 2003; Tronto 2013). Changing these is another more general approach to energy sufficiency (policy). In Fig. 1, the bars and arrows at the top and bottom of the graph indicate this. This was, however, beyond the analysis presented here.

\section{Methods, particularly for policy development}

\section{Overview of the methodological approach}

In this 'Methods, particularly for policy development', we wish to present and discuss the set of methods we developed and used for the micro- and meso-level analysis of energy sufficiency actions and corresponding policies at the level of domains of needs and wants related to electricity use in the residential sector. As we cannot present the full analysis (cf. Thema 2015; Thema et al. 2016) here, we use one domain, clothes cleaning, as an illustrative example (for the reasons to select this domain cf. step 1 below). We consider this novel set of methods as one major result of our work, in addition to the resulting policy package proposal, so we present this in more detail here. The overall results for all domains are presented in 'Instruments supporting energyefficient and sufficient purchase and use of equipment, and other domain-related practices'.

As energy sufficiency aims at limiting or even reducing absolute energy consumption levels, an overarching instrument that would achieve this was analysed as well. This instrument is a cap for energy suppliers on electricity sales to their customers (Sachverständigenrat der Bundesregierung für Umweltfragen (SRU) 2011).

For many end uses of electricity in the home, consumption is correlated with the dwelling floor area per person, although usually not in a linear fashion, e.g. for lighting, refrigeration, and freezing, or TVs. We are not aware of a quantitative analysis of this correlation, but it appears plausible that more room space, which is mostly available to higher income households, allows for more and bigger appliances - also easier to afford to purchase for the wealthier. Due to this correlation of space and electricity use and even more due to the correlation with heating and cooling energy use, instruments for limiting average dwelling floor area per person will be an important part of the energy sufficiency policy package. ${ }^{4}$ In principle, the macro drivers for the growth of percapita dwelling size, such as increasing income and wealth, should also be addressed by policy. However, it is at present unclear how this could be done. We therefore focused our analysis on policies enabling and supporting households to move to smaller homes and a framework of targets and funding for such policies. These policies were identified from a literature search.

For both the electricity sales cap and the per-capita dwelling floor area policy instruments, analysis was much simpler than for the specific instruments targeting the domains of electricity use. We implemented a multicriteria analysis of the objectives, the political and legal feasibility, the agents of implementation and the preconditions they need for success, the details of funding and implementation, and the potential impacts of the policies, most notably their energy savings potential for Germany. Results are presented in 'Instruments for limiting average dwelling floor area per person' and 'Electricity sales caps and trade for suppliers'.

For the analysis of domains of needs and wants, a broad mix of methods was used: Starting from a definition of energy sufficiency (cf. previous section), we performed a criteria-based analysis of options for more energy-sufficient practice, i.e. potential energy sufficiency actions in the household (cf. next subsection on steps 1 to 3 for the methods and an illustrative example; for limitation of space, we kindly refer the reader to Brischke et al. (2015) and Thema (2015)). This process was informed by results of several research efforts in the wider project. These included cultural probes with groups of consumers; qualitative in-depth interviews with 12 people responsible for the caring work in their households; a quantitative survey of 600 of such persons; two co-creation workshops with appliance manufacturers and stakeholders for clothes cleaning and

\footnotetext{
${ }^{4}$ Of course, there are other potential energy sufficiency actions to reduce heating or cooling energy use in homes that are too big, such as not heating or cooling rooms that are not in use. As discussed below, we had to leave these out of the scope of analysis for this research for budget constraints. Also, the novelty of analysis on policy instruments addressing per-capita dwelling size is greater than for these other actions; and making better use of existing dwellings will save other resources in addition to energy.
} 
information and communication technologies (ICT) on alternative product-service systems that could enable the substitution route; design criteria for domestic appliances enabling energy sufficiency; an interdisciplinary focus group with gender-competent experts on the disciplines and contexts concerned (Spitzner and Buchmüller 2016); and an analysis of energy saving potentials from implementing energy sufficiency actions by households and manufacturers. All of this research work also formed the basis for the policy analysis. A more detailed description can be found in Brischke et al. (2016).

Any sufficiency action or intervention follows one of the three basic energy sufficiency approaches defined above - reduction, substitution, and adjustment - and changes the translation chain from basic needs (left side in Fig. 1) to the finally supplied technical service. The first three steps of the analysis concern (1) each requirement, need, or want, (2) the current situation, and (3) the potential energy sufficiency actions for changing practices regarding this requirement, need, or want. Steps 4 to 7 of the policy analysis are presented in the four bars to the right of the graph: (4) the analysis of barriers as well as prerequisites and framework conditions needed for households and their members to make the change in practices happen; (5) the sustainability check: is the action reducing energy and resource demand, and is it socially acceptable? (6) the analysis of the need for energy sufficiency policy to overcome barriers and create necessary preconditions for energy sufficiency actions remaining after steps 4 and 5, and which types of instruments would be appropriate for this purpose, and (7) integrating the single policies to a consistent package.

The next two subsections of this paper will present the methodological motivation, some detail, and an illustrative example for these seven steps.

Defining the scope and potential actions: steps 1 to 3 of the domain-level analysis

For developing an energy sufficiency policy, we need to analyse which potential types of energy sufficiency action in the household exist in principle. These are steps 1 to 3 of the analysis, presented here along with their application for the example of clothes cleaning. The analysis for the other domains of electricity use can be found in Thema (2015).
Step 1 scope: defining the unit of analysis (domain)

In a first step, the unit of analysis has to be defined where higher levels of energy sufficiency shall be reached. Other than with energy efficiency that targets single energy-using products (e.g. washing machines or personal computers), for sufficiency, this involves a domain of needs and wants (e.g. clothes cleaning or information/communication).

Table 1 lists the basic needs (mostly areas of care economy production) that the multi-disciplinary project team identified for the main areas of electricity use in the household, and how these needs translate to different domains of needs and wants (including care economy domains: basically all domains related to food, cleanliness, and personal hygiene). Room climate (heating/ cooling) was not analysed further in detail due to limitations of funding, and since heating is mostly not provided by electricity, so not in the focus of our research (however, Bierwirth and Thomas 2015 provide some analysis). Space cooling so far is not very relevant in Germany's residential sector. However, as we also analysed ways to reduce dwelling floor area per capita or at least its continued growth, both space heating and cooling demand are very much correlated to floor area and hence are addressed in this way.

Example As care economy and gender issues are relevant in residential electricity use, we decided to choose one of the respective domains (see Table 1) for this paper as an exemplary policy case. Most of the needs within the care economy domains vary widely across different households. We decided to choose a domain that is relevant to all households to present as an example. The domain considered to be most relevant was clothing cleanliness, as this is a need to be satisfied by all households. At the same time, clothes cleaning practices are more complex (e.g. Kaufmann 1998) and differ much more widely between households than e.g. food cooling, promising more scientific insight. We were also able to address clothes cleaning practices in a consumer survey on energy sufficiency (cf. step 4 below). For the analysis of other domains, cf. Thema (2015).

\section{Step 2 status quo: analysing current energy consumption hotspots}

Within a domain of analysis, the currently existing hotspots of energy consumption have to be identified, 
in order to search for potential innovations in the next step. In our case, this focused on electricity consumption, but the methodology could of course also be used for other forms of energy. This step is important in terms of effectiveness: If sufficiency is to significantly reduce energy consumption, the hotspots of energy consumption will have to be addressed instead of services that are less relevant in this respect.

Example of clothes cleaning With clothes washing being the dominant cleaning process, this step is not complex. The energy-consuming event in status quo is washing in the washing machine. However, energy consumption may vary strongly with (a) the frequency of washing, (b) the way of usage (well-filled, temperature, spinning), and (c) the type of machine (auto-selection of programme, efficiency class).

\section{Step 3 potential innovations: collecting potential energy sufficiency actions}

In the third step, the potential sufficiency actions, which may contribute to reducing energy consumption, are collected. In our analysis, we used literature search, team brainstorming sessions, and open innovation workshops ${ }^{5}$ (Brischke et al. 2015). The guiding question here is how needs and wants can be satisfied with smaller units and less intensive use or by using different ways of needs fulfilment with lower energy consumption (e.g. external services or entirely differing approaches).

Energy-relevant 'decisions' of private households can be found on various levels. There are many points in daily life, at which there are choices to be made in the transmission chain presented in Fig. 1. Mostly, these choices are embedded in daily routines and social practices, or they may be determined by the infrastructure that exists or not. So they are not 'rational decisions' of an individual as a sovereign economic actor in the classical sense, but as stated above, the wider societal and cultural influences provide the framework for sufficiency actions, within which households and individuals

\footnotetext{
${ }_{5}^{5}$ Contrary to the classical understanding of innovation within a firm, 'open innovation (OI)' refers to the generation of new ideas through the collaboration with external experts and stakeholders. Often, 'OI' is connected with the 'Human Centered Design' approach, searching for innovations optimal for its users. Further literature on OI includes Chesbrough (2003), Fasnacht (2009), Von Hippel (1986), Reichwald et al. (2007), Zhao and Deek (2004), and Walcher (2009).
}

act in a principally rational way. Such 'decisions' can be found:

- Related to the purchase or not of equipment (e.g. purchase of a television)

- Related to the direct utility aspects of equipment such as performance, capacity, technological features (e.g. size of the television screen)

- Related to further utility aspects, such as status symbols, social affiliation or differentiation, health, and esthetical aspects (e.g. an extra-large television with special technological features, as a status symbol)

- Finally, related to the duration or intensity of use of existing equipment or of alternative services

For developing an encompassing list of potential sufficiency actions, these decision levels linked with the three sufficiency strategies presented above (reduction, substitution, adjustment) guided the collection of potential sufficiency innovations. Altogether, around 125 potential energy sufficiency actions for saving electricity in the household were identified (Thema 2015).

Example of clothes cleaning In the washing domain, we distinguished actions that may serve for downsizing (until eliminating) washing equipment in the household from other actions that may serve for saving electricity through changes in equipment use. We also sorted them by the three sufficiency approaches presented above (reduction, substitution, adjustment). Table 3 in the following 'Methods for analysis of what could be appropriate energy sufficiency policy packages: steps 4 to 7 ' lists the possible actions identified, so we do not replicate them here. Some of these potential actions were also subject to the empirical survey performed during the project; results are outlined at step 4 of the analysis below.

Methods for analysis of what could be appropriate energy sufficiency policy packages: steps 4 to 7

Value chains in the building and electricity end-use sectors are complex. Many different actors-investors, end-users but also building developers, equipment or appliance manufacturers, designers, trade, and builders - would have to work together for reducing energy use. A well-designed package of policies and measures is, therefore, needed to assist the various 
actors in overcoming their specific barriers, possibly creating preconditions, and strengthening their incentives. Just as for energy efficiency, we can assume that energy sufficiency actions concerning modifications in appliance design, buildings, or the housing market may need well-designed packages of polices and measures, which interact and reinforce each other in such a policy package (Thomas et al. 2013). The overarching objectives for the policy package on energy sufficiency are to:

- Make it possible (in case there are restrictions)

- Make it as easy and attractive as possible

- Eventually, make it the standard

- In addition, discourage or regulate non-sufficiency

Every policy or measure has its own function in the package, its advantages, target groups, and specific operational mechanisms. Each is tailored to overcome one or a few certain market barriers and to strengthen the actor-specific incentives, but none can address all of these barriers and incentives. Therefore, the impact of well-combined policies is often larger than the sum of the individual expected impact (IEA 2005). In this context, we understand policies as any kind of policy instrument set up by actors from the polity. This may happen at various governance levels (from local to international, depending on the competent jurisdiction).

Energy sufficiency, however, also has a number of potential types of actions that require householders, caregivers, or other household members to reduce the size or features of equipment they buy, modify its use, or even substitute equipment purchase or use by new or traditional services. Such action often concerns the transformation of needs or wants into the reliefs for housework and caring needed or the aspects of utility desired, or transforming such reliefs or utility into the technical service requested (cf. Fig. 1). Making these actions happen will therefore often require policy to overcome restrictions in the household or its environment, to enable sufficiency action (through framework conditions, infrastructures, service offers), and to enable informed decisions. This, hence, requires much more than just individuals 'changing behaviours'. The question is which policies and measures are needed to make these actions happen. And although the 'value chains' for these actions may differ a lot from those in energy efficiency analysis of appliances and building markets, answering this question will also require the analysis of barriers and incentives, but more than for energy efficiency also on acceptabilities of actions, drivers of energy consumption, and framework conditions that shape action in purchasing and using equipment. Particularly, the necessities of the care economy and the imperative of not putting inappropriate burdens on those who do the cooking, washing, and cleaning, but rather to ease their tasks while trying to promote energy sufficiency, have to be considered.

Energy sufficiency policy is a new field. Some policy experience exists, but we are not aware of any integrated comprehensive policy packages being implemented. Therefore, we cannot yet follow the advisable two-step approach of combining (1) an actor-centred theoretical analysis, as we are performing it here, with (2) an empirical proof of which policy instrument advanced countries have packaged together, as it can be done for energy efficiency policies (e.g. Thomas et al. 2013; Rosenow et al. 2016).

The process of analysis leading to the final development of an integrated sufficiency policy package is presented in Fig. 1. Starting from the potential types of energy sufficiency action identified in steps 1 to 3 and presented above, the first two steps in this policy analysis (i.e. steps 4 and 5) concern barriers and prerequisites as well as the question, which of these actually save energy and are socially acceptable to the householder and the household members, especially do not put too high a burden on the caregivers in the household.

\section{Step 4 barriers to implementation: analysing prerequisites and framework conditions}

Every single potential sufficiency action from step 3 has to be analysed in detail as to the framework conditions in which it may be carried out, with respect to prerequisites (or preconditions) that have to be met before the action can be realised by the household and its members and with respect to the interest in action they have. This step is essential, as the implementation barriers will have to be identified that need to be addressed by policy in order to enable the action. Because the areas of food provision and cleanliness/hygiene involve the care economy (cf. definition in 'What is energy sufficiency? The general concept'), the respective pressures on the latter are most important. As the care economy is not yet gender-balanced in most households, gender issues are vital. We identified a series of separate issues that can be analysed for every single possible sufficiency action (Table 2). We started with desktop research on all types 
Table 1 Basic needs and their translation to domains of needs and wants

\begin{tabular}{ll}
\hline Basic needs/area of care economy production & Domains of needs and wants/care economy domains \\
\hline Adequate food provision & Storage, cooling, freezing food preparation \\
Adequate provision of cleanliness/personal hygiene & $\begin{array}{c}\text { Clothes washing/cleaning, clothes drying, dishwashing, } \\
\text { housekeeping, and personal hygiene }\end{array}$ \\
Adequate lighting & Lighting \\
Adequate room climate & Heating/cooling (air conditioning) ventilation \\
Leisure/entertainment/information/communication & Leisure/entertainment/information/communication \\
\hline
\end{tabular}

of basic need. Qualitative in-depth interviews with 12 persons for clothes washing and TV use and a focus group on gender issues provided some empirical insight. The survey of around 600 persons was used to test a number of these potential actions for clothes washing and TV use (Fig. 2).

This step of analysis was done for all ca. 125 types of more energy-sufficient equipment purchasing and using practices identified in step 3 (Thema 2015).

Example of clothes cleaning Wearing clothes longer and airing instead of washing may be at odds with norms demanding that clothes are washed after 1 day of use. Washing only at full loads may require possession of too many clothes for one-person households. Reducing wash temperatures may be difficult for heavy-duty households (families, workers, etc.) or allergy sufferers. Reducing spin speeds will require adequate drying space for wetter clothes and is applicable only in summer, when clothes can be dried outside/without room heating. Washing by hand instead of with the machine means a lot of work. Actions that employ external infrastructures and services will of course have the existence and provision of these as a precondition. This concerns communal laundry facilities in multifamily houses, laundries in the quarter, or laundry services with pickup and delivery at the home, in combination with an additional refreshing cabinet in the home. More detail on the barriers for energy sufficiency actions in clothes cleaning or on preconditions necessary can be found in the second column of Table 3 .

\section{Empirical results of a quantitative survey}

The research project carried out a survey among 600 persons who are responsible for the housework. While this responsibility was the criterion for selecting the persons to interview, the survey is otherwise representative for the German population in terms of income, age, living in own or rented accommodation, education,

Table 2 Issues for up-front analysis of potential sufficiency actions

\begin{tabular}{|c|c|c|}
\hline & Issue for analysis & Description \\
\hline \multirow{3}{*}{$\begin{array}{l}\text { Preconditions for } \\
\text { implementing a type of } \\
\text { action }\end{array}$} & Care economy/individuals & $\begin{array}{l}\text { e.g. time constraints (time needs of an action and its fit to logics of care } \\
\text { organisation), acceptability by caring and cared-for individuals }\end{array}$ \\
\hline & Infrastructures & $\begin{array}{l}\text { Infrastructures necessary for implementation, e.g. within } \\
\text { household/dwelling, local care and service infrastructure/institutions } \\
\text { (public/commercial), transport infrastructure (public/commercial) }\end{array}$ \\
\hline & Policy & Necessary political framework and policies for implementation \\
\hline \multirow[t]{3}{*}{$\begin{array}{l}\text { Effects of non-fulfilment } \\
\text { of preconditions }\end{array}$} & $\begin{array}{l}\text { Type of intervention into logic of } \\
\text { care economy production }\end{array}$ & Estimation of effect on workload: more, none, less \\
\hline & $\begin{array}{l}\text { Degree of relief in care economy } \\
\text { workload }\end{array}$ & $\begin{array}{l}\text { Estimation of degree of relief: ++ (strong relief) to -- (strong additional } \\
\text { workload) }\end{array}$ \\
\hline & Vulnerable population & $\begin{array}{l}\text { Identification of population sections that may be especially vulnerable to the } \\
\text { implementation of the sufficiency action under scrutiny }\end{array}$ \\
\hline
\end{tabular}




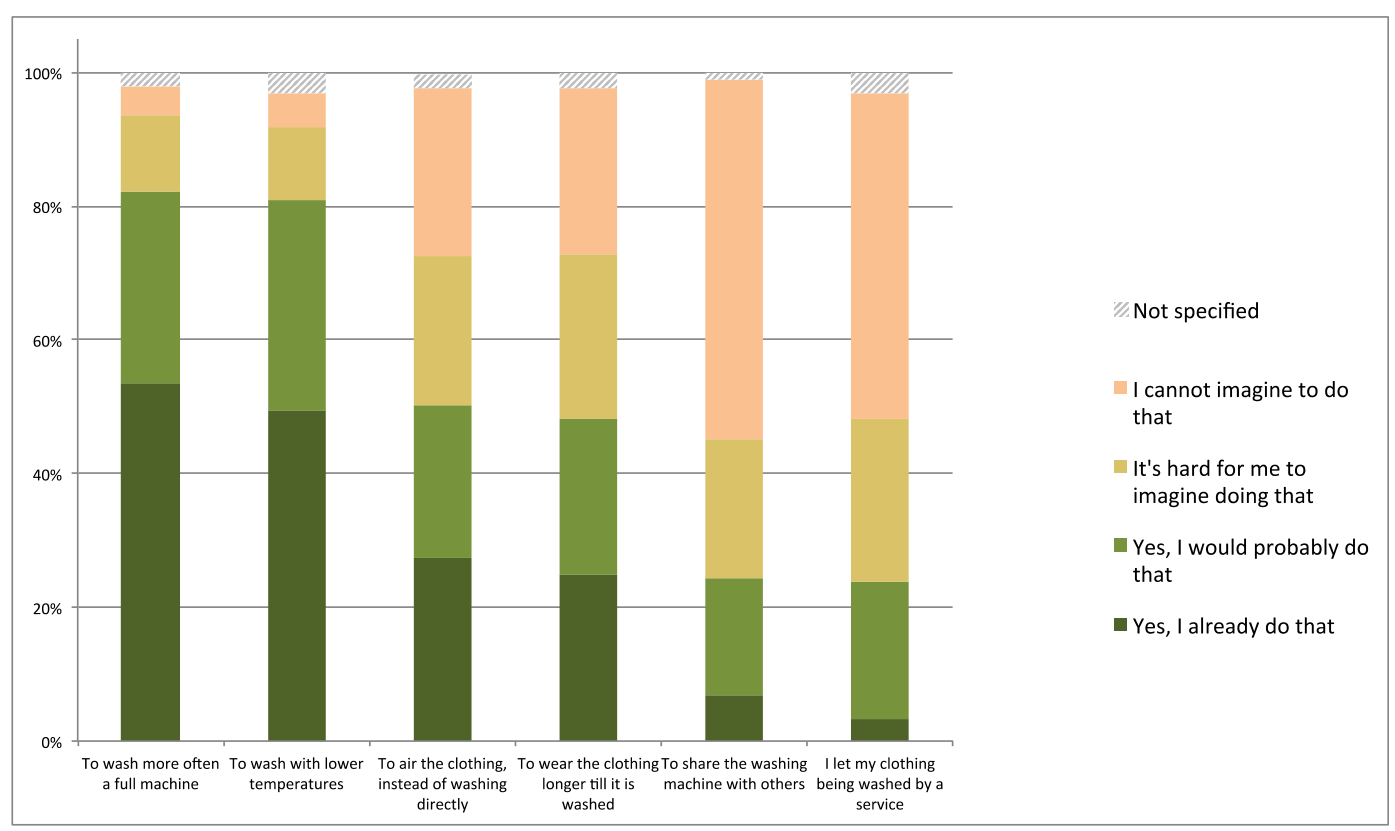

Fig. 2 Answers of interviewees with regard to different aspects of the cleaning of clothes $(N=601$, except for sharing a washing machine: selection of interviewees living in multi-apartment buildings, $N=378$ )

and even gender, although the number of 600 may be too small for it being representative in the strict statistical sense. It built on the analysis of options for more energy-sufficient practices in the household and by individual. Due to time limitations for the telephone interviews, it needed to focus on clothes washing and drying as an example of housework and on entertainment. Facts and perceptions regarding per-capita dwelling floor area were another focus; results on this subject will be presented in 'Instruments for limiting average dwelling floor area per person'.

The survey revealed that many of the households interviewed already carry out energy sufficiency practices, even though most probably never heard of 'sufficiency'. Mostly, these are small changes in daily routines that have been communicated for many years under the labels of 'energy conservation' or 'energysaving behaviour'. An example is practices in clothes washing. More than $50 \%$ of the interviewed stated that they already try to wash full machines and with lower temperatures. Including those who are open to adopt these practices too, about $80 \%$ of interviewees may potentially implement them. In contrast, more profound changes or those running counter to "normal practice', e.g. of how long to wear clothes before they get washed, are practiced less frequently, and there is less openness towards adopting these. For example, only $8 \%$ of those interviewed share the washing machine, thereby reducing embodied energy and the space required (cf. Fig. 2). However, an additional $14 \%$ of respondents, who live in multi-apartment buildings and could therefore potentially share a washing machine, could imagine doing that in the future. Main reasons for others to reject this change are that they do not want to depend on others or they distrust their neighbours. A similar outcome was observed for the alternative of a washing service. The main reasons for the rejection of this type of action are being afraid of strangers coming into the house, intimacy concerns, taking pleasure in washing clothes by oneself, and financial reasons (Leuser et al. 2016).

Step 5 sustainability: excluding potential types of action with negative net effects on environment and care economy

This step is to ensure that energy sufficiency actions are also sustainable in a wider sense. Two sustainability dimensions matter here: the environmental (i.e. ensuring a positive net effect on the environment) and the social dimensions (i.e. ensuring that no significant externalisation of additional work required to save energy into the gendered care economy takes place and that actions are acceptable by caring and cared-for persons). This is in 
Table 3 Energy sufficiency actions, policy needs, and derived energy sufficiency policy instruments for clothes cleaning

\begin{tabular}{llll}
\hline Action & $\begin{array}{l}\text { Barriers (b) or } \\
\text { preconditions (p) }\end{array}$ & Main policy needs & $\begin{array}{l}\text { Adequate policy } \\
\text { instruments }\end{array}$
\end{tabular}

\section{Actions for downsizing equipment}

Longer usage period of clothing Norms of fresh clothing (b); clothing that soon looks or smells 'dirty'

Support change in norms: longer usage periods for many clothes possible; make clothes available that do not so quickly look or smell 'dirty'

Wash only full drums

Habits (b), sufficient amount of clothes (p), storage (p)

Enable change in habits, inform about energy savings (if clothes and storage already exist), ensure availability of smaller washing machines

Community facilities

Laundry shop

Laundry service and refreshing cabinet (new appliance replacing the clothes washer)

Actions changing utilisation

Longer usage period

More airing
Existence of such facilities (p); Support: financial, targeting fear of social control/problems with intimacy (b)

Existence of nearby such facilities (p); fear of social control/ problems with intimacy (b); effort, distance to be covered (b)

\section{Availability of service (p)}

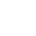
private/public facilities

Ensure reliably available
Ensure locally/reliably available (locality), ensure financial access of low-income households private/public service, ensure pos. Env. effect, ensure financial access of low-income households instruments

Information/publicity campaigns, energy sufficiency advice; initiatives, possibly incentives for clothes that do not rapidly look or smell 'dirty'; or making that feature a requirement for all clothing

Information/publicity campaigns, advice; change European Union (EU) energy label for washing machines to reward low absolute energy consumption per wash (instead of per kilogram of load), legal requirements for appliance design to provide a loading level feedback device

Financial incentive programme, investment in public laundries; information/publicity campaigns and energy sufficiency advice, legal framework for local availability

Financial incentive programme, public investment, including laundry cost in social benefits; information/publicity campaigns and advice assuring potential users that there will be no problems of hygiene

Public investment, including cost in social benefits; information/publicity campaigns and advice assuring potential users that there will be no problems of hygiene; financial incentive programme for market introduction of refreshing cabinets?

(See above)

Norms of fresh clothing (b); clothes that are not adapted for airing (b) or that are adapted (p); space available for airing (p)
(See above)

Support change in norms: longer usage periods for many clothes possible; make clothes that are adapted for airing available, make space for airing available
(See above)

Information/publicity campaigns, energy sufficiency advice; initiatives, possibly incentives for clothes that are adapted for airing; or making that feature a requirement for all clothing; oblige landlords and communities of dwelling owners to allow airing outside, e.g. on balconies 
Table 3 (continued)

\begin{tabular}{|c|c|c|c|}
\hline Action & $\begin{array}{l}\text { Barriers }(b) \text { or } \\
\text { preconditions }(p)\end{array}$ & Main policy needs & $\begin{array}{l}\text { Adequate policy } \\
\text { instruments }\end{array}$ \\
\hline Wash only full drums & (See above) & (See above) & (See above) \\
\hline Reduce temperature & $\begin{array}{l}\text { Habits, fear of insufficient } \\
\text { cleanliness (b) }\end{array}$ & $\begin{array}{l}\text { Enable change in habits, inform } \\
\text { about new detergents and } \\
\text { routines to ensure cleanliness }\end{array}$ & $\begin{array}{l}\text { Information/publicity campaigns, } \\
\text { advice; support R\&D on new } \\
\text { detergents, analysis in their use, } \\
\text { and routines to ensure } \\
\text { cleanliness; possibly legal } \\
\text { requirements for detergents }\end{array}$ \\
\hline $\begin{array}{l}\text { Reduce spinning speed (if no } \\
\text { clothes dryer is used and } \\
\text { clothes are not dried in heated } \\
\text { room); (also: increase } \\
\text { spinning speed if dryer is } \\
\text { used) }\end{array}$ & $\begin{array}{l}\text { Adequate drying space for } \\
\text { wetter clothes }(\mathrm{p})\end{array}$ & $\begin{array}{l}\text { Encourage/allow outdoor drying; } \\
\text { support: financial, targeting } \\
\text { building owners for providing } \\
\text { space }\end{array}$ & $\begin{array}{l}\text { Regulations for washing machines } \\
\text { to provide such programmes, } \\
\text { along with the necessary } \\
\text { warnings for drying; possibly } \\
\text { change housing regulations or } \\
\text { norms; requirements or } \\
\text { financial support for providing } \\
\text { unheated drying space in new } \\
\text { build, especially of social } \\
\text { housing, if not requiring a lot of } \\
\text { material/embodied energy; or } \\
\text { requirements for retaining } \\
\text { existing cold drying space in } \\
\text { existing buildings }\end{array}$ \\
\hline
\end{tabular}

fact a normative political objective we assumed for our analysis, for reasons of sustainability.

A negative environmental effect is probably possible only for sufficiency actions that follow the substitution approach, i.e. replacing current routines, actions, and appliances by alternative ways of satisfying the needs. If the action follows the reduction or adjustment approach, the environmental effect will certainly be positive. A positive net effect of a substitution action may be obvious too (e.g. when replacing a refrigerator by an already existing cool cellar storage) and, if so, will not require further investigation. However, in many cases, substitution actions and their net energy effect may be more complex and require a more detailed analysis as to their total energy savings within the household and additional energy consumption within and outside the household (e.g. when replacing a domestic service production such as washing or food preparation by external services). This kind of analysis is not trivial and requires substantive efforts we were not able to take during this analysis, but it will be necessary to identify which options for energy sufficiency action are environmentally sustainable and could hence be supported by policy.

A negative effect on the care economy or on vulnerable parts of the population should also be avoided. In step 4, actions were also analysed with respect to their barriers and preconditions in that respect. In this step 5, all actions for which the preconditions cannot be met (for physical, political, or other reasons) need to be eliminated from the list.

This analysis resulted in a list of sustainable options of energy sufficiency action that may be targeted by policies. In total, still 84 were retained for the further analysis (Thema et al. 2016).

Example of clothes cleaning Based on the heavy workload and time it requires (which would place a high additional burden on the care economy, with its current gender imbalance), we take manual washing off the list for reasons of social unacceptability. While nothing precludes individuals from doing this, we do not see it fit for policy support (which would exert social pressure anyway) or even regulation. Although further analysis is needed as to the circumstances under which communal laundry facilities in multi-family houses, laundries in the quarter, or laundry services with pickup and delivery at the home, in combination with a refreshing cabinet in the home that replaces the washing machine will actually save energy and/or care economy workload, we keep these in the analysis, but with a caveat. 
Step 6 policy approaches, part 1: deriving policy action needs for the sustainable types of energy sufficiency action

Based on steps 1 to 5 , every single potential energy sufficiency action that may help saving energy in the domain at stake has to be checked with respect of barriers impeding implementation or preconditions needed for it. These define the need for political action in order to make its implementation possible and actually happen. A first starting point is the up-front scan of necessary basic political framework conditions within step 4 .

For enabling single energy sufficiency actions, it is most crucial that all barriers are overcome and that preconditions eventually needed for implementation are met. A good policy thus has to respond to any issues arising from the analysis in step 4, including gender issues and the identification and solution of possible vulnerabilities within parts of the population. To these ends, adequate policies need to be developed. The toolboxes of existing policies may be used, e.g. of energy and energy efficiency policies. However, as shown above, energy sufficiency is very distinct in several respects and will probably require the development of new policy approaches. While we performed a desktop analysis of potentially adequate policy instruments based on experiences from the energy efficiency field, we were able to test the effectiveness and acceptance of some of the underlying options for energy sufficiency action in the survey.

Example of clothes cleaning For our example, possible sufficiency actions resulting from steps 1 to 5 are presented in Table 3. We differentiate between actions that serve for downsizing equipment and actions that target a different use of technical appliances in the washing field. As several actions serve both ends, they appear twice in Table 3.

\section{Step 7 policy approaches, part 2: bundling policies into an integrated strategy}

In the final step, the array of policies identified as supportive to the implementation of the single types of energy sufficiency action within the domain at stake has to be combined into an encompassing and integrated policy package that is addressing all domain issues in an adequate way. In this section, we only discuss our illustrative example of clothes cleaning. In 'Results: the energy sufficiency and efficiency policy package resulting from the analysis' that follows, the integrated policy package will be analysed and discussed in more detail. 'Instruments supporting energy-efficient and sufficient purchase and use of equipment, and other domain-related practices' presents the domain-specific policies analysed in steps 6 and 7.

Example of clothes cleaning From Table 3, we conclude that promoting the energy sufficiency actions we found useful and sustainable for the domain of clothes cleaning will need a combination of information/ publicity campaigns, personalised energy sufficiency advice, changes in the EU energy label and energyusing product regulations, possibly changes in housing regulations or norms, and financial incentive programmes and/or public investment for communal laundry facilities in multi-family houses, laundries in the quarter, or laundry services combined with refreshing cabinets in the home instead of washing machines.

\section{Results: the energy sufficiency and efficiency policy package resulting from the analysis}

In this section, we present a summary of the findings of our analysis on the policy package to support energy sufficiency for residential sector electricity use. All instruments target the micro-level of the individual and/or the meso-level of the household and its environment (building and neighbourhood). The policy package includes both the combined policies to enable and support the micro- and meso-level energy sufficiency actions ('Instruments supporting energy-efficient and sufficient purchase and use of equipment, and other domainrelated practices') for all utility domains that we analysed with the set of methods presented in 'Methods, particularly for policy development', and some further overarching instruments, e.g. for energy pricing and addressing average dwelling floor area per person ('Instruments for limiting average dwelling floor area per person' and 'Electricity sales caps and trade for suppliers'). 'Overview of the methodological approach' discusses why we analysed these latter instruments. As they are overarching the domain-specific policies, we present the results for them first. For a fully integrated policy package, an analysis of instruments to control the macro drivers of energy consumption would need to be added (Thomas et al. 2015). However, this was not 

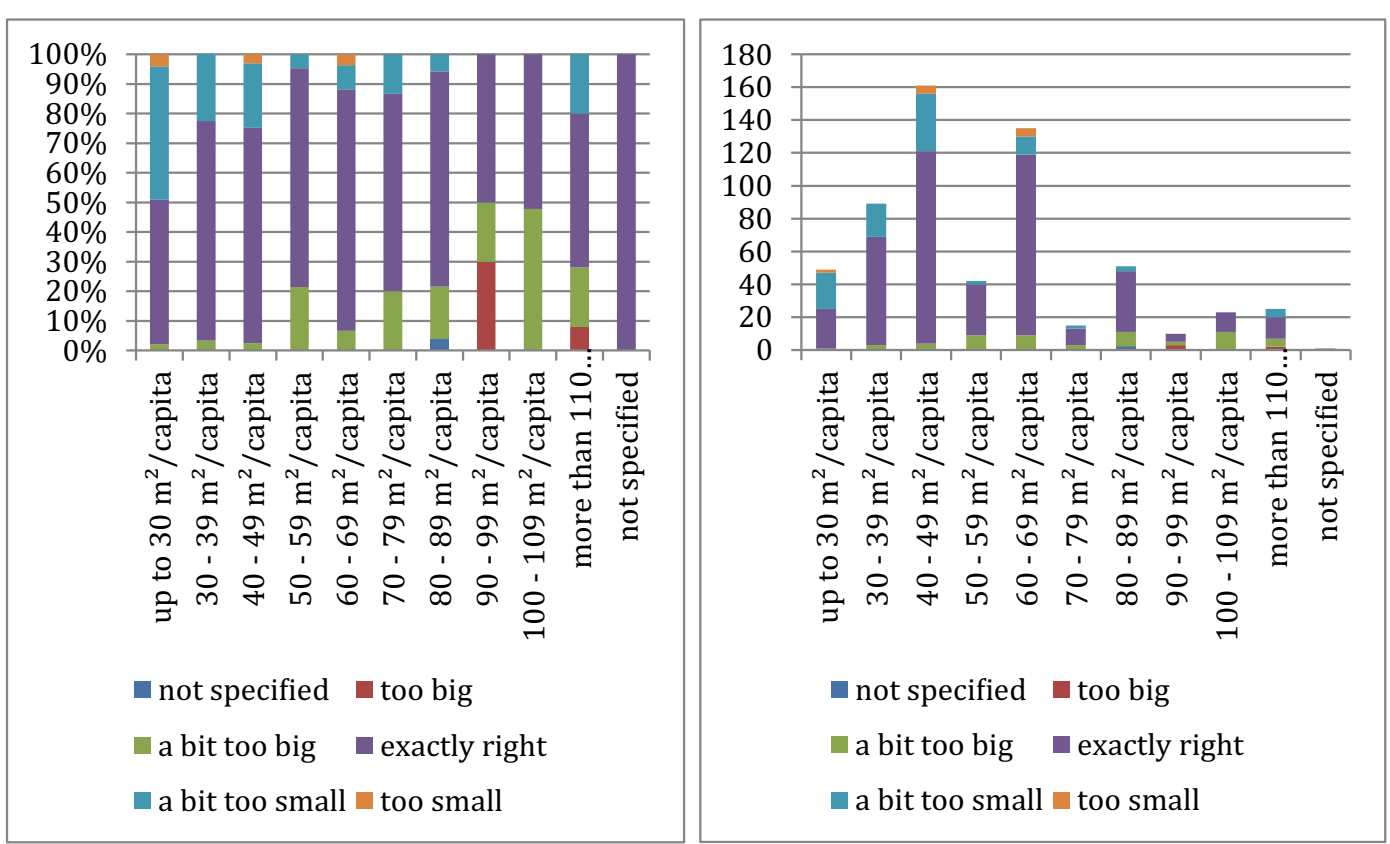

Fig. 3 Answers of interviewees to the question of how they would assess their dwelling with regard to the size in relation to the per-capita living space they live on (left diagram: percentages; right diagram: number of respondents $(N=601)$ )

possible in this project. Therefore, we aimed at an integrated policy package for energy sufficiency and efficiency at the micro- and meso-levels.

As stated in the introduction, policy will need to promote efficiency and sufficiency in an integrated way to achieve absolute energy savings targets. This includes avoiding that energy efficiency measures may run counter to goals of energy sufficiency, as we found e.g. for the EU's ecodesign and labelling regulations: These define energy efficiency per unit of clothes or dish load, which rewards manufacturers and retailers for selling bigger appliances, as it is easier for these to achieve better energy efficiency ratings. ${ }^{6}$ Therefore, some instruments of the energy sufficiency policy package may be the same as for energy efficiency — such as energy taxation and linear or progressive electricity prices. Some may simply adapt technology-specific energy efficiency policy instruments. Examples are progressive appliance efficiency standards, standards based

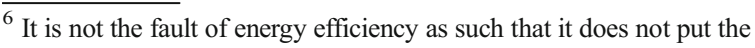
level of utility or service from energy into question: a constant utility level is simply the basis for the very definition of energy efficiency. This is crucial for distinguishing it from energy sufficiency. Addressing total energy use, it is clear that efficiency and sufficiency are two sides of the coin when it comes to saving energy, and it is hence the duty of policymaking to promote both in an integrated and consistent way.
}

on absolute energy or water consumption instead of consumption per kilogram of clothes or per dish setting, or providing energy advice. However, sufficiency may also require radical new approaches, often linked either to substitution routes strongly different from the current technology and practice or to addressing the drivers of non-sufficiency. They may hence range from promotion of completely different services for food storage and preparation or for clothes cleaning, to instruments for limiting average dwelling floor area per person, or to a cap-and-trade system for the total electricity sales of a supplier to its customers, instead of an energy efficiency obligation. In the following subsections, we expand on a number of these policy instruments. Instruments for limiting average dwelling floor area per person will be presented first, followed by a special instrument setting an overall cap on residential electricity sales and finally by the essence derived from the seven-step micro/meso analysis of the domains of energy use presented in 'Methods, particularly for policy development'.

Instruments for limiting average dwelling floor area per person

Events in life such as children moving out to their own household, divorce or separation of partners, or the 
death of a partner will create phases, during which routines and practices may change dramatically. Usually, this will also have a financial impact. In general, pensioners could also be interested in smaller living spaces. For some people, big living spaces are not only a luxury that is enjoyed but also a burden. This space not only needs to be heated, but also has to be cleaned and cared for. Such phases or situations are, therefore, also a window of opportunity for policy instruments supporting the move to a smaller apartment or the (sub-)letting of a part of the house or flat. Again, we do not wish to specify what could be a universal 'sufficient' target level of square metres per person, but just analyse how policy could motivate, enable, and support people to move to smaller dwellings.

Households willing to move face, however, two main difficulties. First, the rent even for newly rented smaller flats is often higher than the current one for a big flat, in which the tenant may have lived for many years. ${ }^{7}$ Secondly, people want to stay in their neighbourhood, where they know the infrastructure and have their friends and social networks.

In this project, we therefore analysed concrete instruments to support the move to a smaller dwelling, forms of communal housing, or the (sub)letting of a part of the home or flat. We see a major role in implementation for the municipal administrations, which however will need legislative and financial support from the federal and state governments. Three particular instruments were analysed in our project:

- Municipal living space agencies, offering a combination of living space advice, practical support for moving, and the provision of financial support

- Financial incentives for alternative forms of housing and for the dwelling space needed for them

- A cap for municipalities on dwelling floor area per inhabitant as an overarching instrument

How big is, then, the potential for people moving to smaller homes? In the survey for this research, $10 \%$ of

\footnotetext{
${ }^{7}$ Germany does not have general rent control (except for new rentals in some cities), but this tendency can still be observed for a number of reasons: older buildings may have lower comfort standards than newer buildings, and rents for new rentals increased significantly in recent years in many cities, while rents in older contracts did not keep up. The latter may be due to a combination of the legal requirement to announce rent increases in written form and in advance, and landlord inertia or reluctance to engage in potentially conflict-prone processes of rent increases.
}

the interviewed think their flat is 'too big' (see Fig. 3). Their living space per capita averages about $78 \mathrm{~m}^{2}$. They are typically owning the flat and are older citizens (54.4\% are older than 60 ) and are single or in couple.

Ten percent perceiving their homes as "too big" may not seem a lot of potential. However, we also asked people under which conditions, including the support through the concrete policy instruments we analysed, they may consider moving to smaller homes. Results will be presented below.

Municipal living space agencies: living space advice, practical support for moving, and the provision of financial support

In addition to two barriers mentioned above, moving to another home requires a lot of effort and money for the search, the renovation, and the actual moving. When moving to a smaller dwelling, there may be excess furniture. Because of the many barriers, we estimate that municipal living space agencies should provide a combination of living space advice, practical support for moving, and financial support. Practical support could concern, e.g., the search for a smaller dwelling and the organisation of the moving. Support to swapping dwellings between growing young families and elderly households reducing in members could be of interest too. The combination appears able to overcome these barriers for many more households than each instrument alone ever could. For example, the effectiveness of information platforms for dwelling exchange is very limited, as the survey confirmed, with less than 5\% saying this would be enough. Especially for households moving into a dwelling they own, the advice should be combined with an individual energy efficiency and sufficiency advice.

The financial incentives will be needed for many households to overcome the manifold barriers. In some cases, it may not even save money to move to a smaller dwelling (cf. footnote above). Such incentives should be funded by the central government, but handed out or allowed by the municipal agencies. They could take several forms, such as waiving a tax for the acquisition of real estate, or property taxes for some time. Bonus payments to older couples who sell their houses in favour of bigger families might be possible as well. Tenants could receive direct payments or an aid to the new rent for some time, and all could receive a grant on the costs of moving. Incentives could also be given to those sharing their dwellings. 
Potential What is the potential impact of supporting a move through policy instruments? For example, $7 \mathrm{TWh}$ of heating energy could be saved a year if by $2030,20 \%$ of the four million pensioner households in Germany decided to move into smaller flats or share the flat with others. This corresponds to 1.81 million $\mathrm{t} \mathrm{CO}_{2}$ /year (cf. Fischer et al. 2016). According to the survey results, the potential of those who could already today consider a move in any case or with the support of the instruments is 10 to $15 \%$. With fewer persons per household in the future, this potential will increase to 17 to $23 \%$. This is about ten times the number of households on which Fischer et al. (2016) based their calculation of the energy saving potential cited here above.

\section{Financial incentives for alternative forms of housing with smaller per-capita area and the dwelling space needed for them}

For Germany, Fischer et al. (2016) found that the number of small apartments is too small to allow a big exchange of dwellings at the current average number of people in the household. One solution could be to provide incentives for separation of large homes or flats to smaller ones. Our survey, however, suggests that what people want is rather to move back into bigger communities, such as shared flats or multi-generational living. Large potential therefore seems to rest in the support for such projects. If, for example, older people leave their houses, they will look for barrier-free apartments. If the apartment is small and the children come for a visit, it will be necessary to have guest rooms. In cities with shortage of dwelling floor space, such approaches are occasionally already applied today. In addition to shared flats or multigenerational living, they include other communal housing projects with shared rooms for fitness, hobbies, festivities, and guests, but also the re-use of already existing buildings, including non-residential buildings. Some examples were presented in Thomas et al. (2015).

In addition to financial incentives, policy may also support such approaches e.g. through public architectural competitions or requiring that any such competitions should include guidelines and requirements for less living space per person.

Potential If households with at least two people are asked what they would do if their household size shrank in the future, $22 \%$ of these households $(13 \%$ of all respondents) can imagine to move to a shared apartment, and even $29 \%$ of these households (17\% of all respondents) can imagine to live in a multi-generation house. This is likely to be the case for many of those living as a single-person household too. It will probably take many years to enhance the supply of buildings for multigenerational living to the level needed to satisfy such a high demand even with a financial incentive programme, whereas the reconstruction of dwellings supporting shared households may be possible much more quickly. Still, we expanded on communal housing and how it could be supported by municipalities in a case study.

Because of the identified benefits that communal housing possibly brings about, we investigated governance options to support and foster these projects. A case study on existing and possible improvements of governance measures in Heidelberg, including a literature review of measures in other municipalities, was carried out (Duscha 2016). The identified governance measures that may support communal housing include the following:

- Including a reduced or at least not an increasing average per-capita living space as conditions for financial support schemes

- Including additional benefits or separate financial support schemes for shared spaces in communal housing and multi-apartment buildings, under the condition that they replace a larger area of individual space

- Creating informational offers like leaflets or advice services (help desks) for interested people

- Integrating communal housing in the urban development plans of municipalities

- Creating lighthouse projects to inform the broader public of these modern, multi-benefit forms of living

Nevertheless, communal housing is not the only means by which per-capita living space can be stabilised or decreased. The co-benefits include other services that can be organised together, social events, shared maintenance, and social benefits through a less anonymous environment.

A cap to municipalities on average dwelling floor area per person as an overarching instrument

A nation-wide cap for existing and new living space would make the incentive and conversion programmes discussed above even more attractive to municipalities. Cities e.g. in Germany are in competition with each 
other. They are also competing for inhabitants, as each additional taxpayer will increase the income of the city. Interesting new building projects in the housing market are created to attract young families. Thus, it is difficult for the cities to restrict any new build activities: they fear the advantage for neighbour cities. This problem may only be solved by establishing a common target for floor space consumption applicable to all German cities and towns. It should be noted that the proposal we analysed would be to set the cap for the municipality. This would translate to an average floor area per inhabitant but not an individual maximum. We also do not specify a target value for a (reduced) average. The first policy objective would be to halt further growth in average and overall dwelling floor area, before even starting to aim at a potential reduction.

A more radical approach for such a regulation might hence be to allow the building of new, additional houses only in cities with a growing number of inhabitants. Such a regulation would potentially be the most powerful, but certainly a very contentious instrument. As required, municipalities may be allowed to buy or sell rights of dwelling space from or to shrinking cities or towns. This would satisfy the needs of growing cities but also give an incentive to all municipal authorities to limit new build of dwellings.

In practice, municipalities will only be able to stay within the cap through providing the kind of financial incentive programmes and services for reconstruction and moving to their citizens as discussed above. Only with such programmes will it be possible to avoid shortages and excessive rents or purchase prices, and make the cap scheme acceptable. Therefore, the central government will also need to accompany the cap by adequate funding to local authorities. An alternative may be to give the task of implementation and/or funding to energy companies (cf. next section of this paper).

Still, the political resistance against such a legal cap could be too high. In this case, the cap could be set as a strategic but non-binding policy target. The federal and provincial (Länder) governments would need to monitor compliance with the target and support meeting it through the other instruments discussed above, in connection to regional planning that aims at a balanced development between municipalities in a region.

There are several options for funding the overall housing policy package. They include using revenues from property (acquisition) taxes or energy taxes. $\mathrm{Mu}-$ nicipalities will save on costs for preparing land for construction. In addition, a luxury tax could be levied for dwellings above a certain size. This would avoid the social problems that come along with a general dwelling space tax (cf. Fischer et al. 2016), which are the reason why we do not propose such a general tax.

Potential In principle, the cap on dwelling floor area could fully implement the potential for limiting the growth of floor area, in conjunction with the other instruments aiding compliance with the cap. For example, Matthes et al. (2013, p. 25) expect total dwelling floor area in Germany to grow by $6.4 \%$ between 2015 and 2030. Per capita, this means an increase of $10.8 \%$, from 40.7 to $45.1 \mathrm{~m}^{2}$. The latter is just a little higher than the existing dwelling stock in 2015, which was $44.2 \mathrm{~m}^{2}$ per capita, including $8 \%$ of empty dwellings. If Germany succeeds in avoiding the net addition to the stock of $0.21 \mathrm{bn} . \mathrm{m}^{2}$ and assuming an average energy consumption for heating and hot water of $70 \mathrm{kWh} /\left(\mathrm{m}^{2} * \mathrm{a}\right)$ and a greenhouse gas intensity of $0.23 \mathrm{~kg} / \mathrm{kWh}$ (natural gas), the cap will save almost $15 \mathrm{TWh} /$ year of energy and around $3.4 \mathrm{mn}$. tons of $\mathrm{CO}_{2 \mathrm{eq}} /$ year of greenhouse gas emissions. If residential electricity consumption is proportional to dwelling size too, electricity savings of $8.4 \mathrm{TWh} /$ year and greenhouse gas emission reductions of $4.2 \mathrm{mn}$. tons $\mathrm{CO}_{2 \text { eq }}$ year may be added.

For 2050, current projections already foresee a stabilisation of total residential floor area, so a cap on this total would not bring any further savings.

This example also shows: The population level effect of dwelling area policies will depend on the situation in the housing market. If there is a shortage of dwellings, such policies will help to utilise the existing stock better and thus reduce the need for building new dwellings. If there is already underoccupation of dwellings, the overall effect will likely be limited, unless dwellings are demolished. Under a cap for municipalities, those with a growing population could reward those with a shrinking population for demolishing unoccupied buildings. The calculation of the potential for Germany is taking the underoccupation into account: in the scenario for 2030, first, the underoccupation is assumed to vanish, before new build is avoided. Considering past trends of increasing average per capita floor space, that would be the first aim of such policies: limiting net new build. Recent trends in Germany, with numbers of new-built dwellings soaring following increase in population, show we are far from achieving this, and there is not even a public discussion on it. 
Electricity sales caps and trade for suppliers

Just as the cap on dwelling floor area would be setting a target towards overall-and hence, average - more sustainable levels of consumption, the domain-specific energy sufficiency actions and policies could also benefit from a similar target-setting instrument. An innovative instrument of that kind was proposed by the German Advisory Council on the Environment (Sachverständigenrat für Umweltfragen, SRU) in 2011, and so we analysed its usefulness and feasibility. It is a cap-and-trade scheme for all electricity suppliers in the country on their sales to private households. Its basic way of functioning is as follows:

In the beginning, certificates will be produced for the total amount of allowed electricity sales in the starting year and allocated to suppliers based on their number and type of customers. This total amount of certificates will be reduced in subsequent years, following a predetermined path. Suppliers will have to hand in the exact amount of certificates matching their sales each year. If a supplier meets its target, i.e. the number of certificates allocated is the same as its electricity sales in $\mathrm{kWh}$, there will be no need for further action. If the customers saved more energy than targeted, the supplier may sell surplus certificates or bank them. If a supplier cannot support its customers to realise enough savings, it will need to purchase the missing certificates from other suppliers with a surplus. This trading element can therefore create flexibility and improve economic efficiency. This instrument would thus be similar to the energy efficiency obligation schemes (EEOS) or 'white certificates' schemes that exist in the EU, but modify the obligation to an absolute reduction in electricity sales, instead of the current targets for energy savings relative to a baseline. It puts the obligation on the supplier, not the individual, which distinguishes it from proposals for personal carbon trading (on the latter, e.g. Fawcett and Parag 2014). Both approaches have relative advantages or disadvantages, a discussion of which is beyond the scope of this paper.

The sales cap scheme provides a strong incentive for suppliers to support their customers in reducing their electricity consumption through energy efficiency, energy sufficiency, or fuel switching. They have complete freedom as to the ways and services they use to support their customers in reducing their electricity consumption. This is, hence, a policy addressing another important driver of energy consumption and non-sufficiency: the incentive that energy companies have had to increase energy sales. However, a number of details need to be clarified, and its consequences better analysed before such a scheme could be started. For lack of space, we can only present the results here.

We found that such an electricity cap and trade scheme is legally feasible in Germany and is likely to be highly effective in reducing the electricity consumption of the customers included. It will need both energy sufficiency and energy efficiency to stay within the sales caps, if these are set ambitious enough. In order to implement most of the potential for energy sufficiency and efficiency in Germany that is additional to recent baseline trends, the sales cap would need to be reduced by around $3 \%$ each year. The scheme will be easy to combine with almost all policy instruments and programmes recommended following the analysis at the micro- and meso-level, possibly including those aiming at the limitation of average dwelling floor space-financial incentives, information, and advice would be offered by the obligated energy companies to their customers. It is likely also easy to combine with existing policies and measures, if interactions are sufficiently analysed and addressed.

However, there are still many questions in detail that need to be resolved before implementing such a scheme. These include the sectors covered (only residential or others too?) or whether it should be a mere electricity sales cap (carrying the risk of fake savings through fuelswitching away from electricity) or a full energy sales cap, which will create a lot of further questions. When adding other fuels than electricity, the unit for the cap needs to be analysed: primary or final (sold) energy, or even emissions, when taking renewable energies and the fuels used for power generation into account. In detailed design, there are questions such as the stochastic fluctuations of consumption between years and between households, and how to avoid undesired effects such as adverse selection - there may be an incentive for obligated energy companies to acquire customers with high or low energy consumption, depending on the rules of setting the baseline.

Due to these open questions, we cannot recommend to implement this new instrument right away but to test it in a pilot scheme. In the short run, governments should implement the micro-/meso-level instruments summarised in the next subsection themselves. In Germany, e.g. the energy efficiency fund of the federal government could be given the additional task of 
promoting energy sufficiency, along with the necessary funding (Thomas et al. 2013b).

Instruments supporting energy-efficient and sufficient purchase and use of equipment, and other domain-related practices

This section presents the proposed domain-specific and energy pricing policy instruments that resulted from steps 6 and 7 of our analysis on the domains of needs and wants satisfied through electricity use in the household (cf. 'Defining the scope and potential actions: steps 1 to 3 of the domain-level analysis') and that would support the many micro/meso energy sufficiency actions in the home we had identified in steps 1 to 5 . The resulting subset of policies is partly domain-specific, partly addressing all domains alike. The analysis was done for all domains listed in Table 1 except adequate room climate, in the same way as outlined for the illustrative example of clothes cleaning in 'Methods, particularly for policy development'. The full analysis was published by Thema et al. (2016; in German). The following is a synthesis of the results by broad types of instruments that, according to our analysis, would need to reinforce each other as part of the micro-/meso-level energy sufficiency policy package and be backed with an overarching framework instrument, such as the electricity sales cap (cf. 'Electricity sales caps and trade for suppliers') or an energy efficiency and sufficiency fund.

\section{Energy pricing instruments}

Energy taxation is an instrument to internalise external costs of energy supply into energy prices. It thereby increases the energy prices and hence the economic motivation to save energy. This motivation supports both energy efficiency and energy sufficiency alike. Some have observed that energy taxation and the signal for energy sufficiency it sends can also be a measure to counterbalance the rebound effect from energy efficiency action and policy. However, energy taxation alone will not be sufficient to overcome barriers that are not related to the energy price. The other instruments analysed here will therefore be needed in addition to realise closer to the full potential, for both energy efficiency and sufficiency. These instruments should particularly support energy-poor and other vulnerable households in tapping the potential for energy and bill savings through energy efficiency and sufficiency, as they may otherwise be relatively more affected by energy pricing instruments.

The same holds true for linear or progressive energy prices. They both improve the price signal for saving energy, including through energy sufficiency. However, currently the energy policy debate is rather for more fixed price elements to cover network and reserve costs also for those who self-generate with solar PV, hence even more degressive energy prices. Maybe energy sufficiency can provide an argument against such trends.

\section{Sufficiency-oriented product policy}

For appliance energy labels and standards, a sufficiencyoriented product policy implies a move from specific to absolute metrics (e.g. $\mathrm{kWh} /$ cycle not $\mathrm{kWh} / \mathrm{kg} /$ cycle) and from linear to progressive requirements. In our example of clothes cleaning, the current EU energy label has energy efficiency defined in relation to a baseline calculated in terms of $\mathrm{kWh} / \mathrm{kg} / \mathrm{cycle}$, i.e. per kilogram of full load capacity of the washing machine. Even though an intercept value was introduced, it probably still is easier for manufacturers to achieve the highest efficiency label classes $\mathrm{A}+++$ and $\mathrm{A}++$ with larger machines, so this is a clear signal to increase capacity. This may well have been a driving force behind the observation that currently clothes washers with 7 or $8 \mathrm{~kg}$ of capacity dominate the market, while 20 years ago, $5 \mathrm{~kg}$ of capacity was most common (Ecofys 2014). This trend is a barrier to energy sufficiency, which would call for smaller appliances. Defining the energy efficiency baseline in $\mathrm{kWh} /$ cycle may be able to revert this trend and hence support energy sufficiency in the purchasing decisions of EU households. Similar changes may be required for other types of appliances. For refrigerators or TV sets, e.g. progressive standards with a maximum absolute level would be appropriate (Calwell 2010); for other product groups, an absolute maximum energy consumption alone may be sufficient, as is already the case for vacuum cleaners.

Labelling and ecodesign requirements should also oblige manufacturers to install an automatic switch-off after a time to be determined for appropriate types of equipment. All programmes and settings should directly display the data on their electricity consumption (such as for washing and drying cycles, filling level of kettles, refrigerator settings, radiator thermostats). ICT appliances should carry clear information on whether they 
are compatible with multiple operation systems or which functions they offer.

Brischke et al. (2015) present more detailed conclusions for the future development of energy labelling and ecodesign.

\section{Energy sufficiency advice}

As for energy efficiency, lack of information and motivation can be an important barrier to implement energy sufficiency actions in the purchase and use of appliances or the alternatives. Information alone will not be enough but is needed nevertheless. It should be motivating, e.g. by stating what the individual and the country as a whole could save (energy, GHG emissions, costs), and intriguing by allowing the recipient to compare his/her routines with 'what others do'. Personalised energy sufficiency advice can be much more effective than general publicity and information campaigns in making people aware of their own options and in convincing them of advantages or that e.g. perceived health risks are not a problem. For cost and effectiveness reasons, such advice should be integrated with advice on energy efficiency options.

In our example of clothes cleaning, advice would particularly concern actions such as wearing clothes longer, airing instead of washing, washing at full loads only, and reducing wash temperatures and spin speeds, unless a drier is used. It could also relate to actions that need external infrastructures and services if these were available in the building or neighbourhood, such as communal laundry facilities in multi-family houses, laundries in the quarter, or laundry services in combination with an additional refreshing cabinet in the home, and to financial incentive programmes for any of these.

\section{Financial incentives}

Financial incentives, such as grants or tax deductions, may be justified for the purchase of energy-sufficient products, e.g. smaller washers, refrigerators, or TV sets. Vice versa, higher taxes could be levied on less sufficient products. Waiving the scrapping costs for old but still working appliances would be an incentive for scrapping instead of keeping them, when a new one is bought anyway, and would thereby promote energy sufficiency. Promoting and facilitating repair instead of purchasing new appliances may not always reduce energy consumption but be a sufficient practice saving resources too.

\section{Promotion of energy-sufficient services}

In some cases, energy-sufficient services can be substitutes for appliances we use today in the home. Their market breakthrough may require promotion through public awareness, information, and motivation programmes, but their establishment may also need financial incentive programmes and/or public investment, at least for some initial demonstration facilities and businesses.

In our example of clothes cleaning, to the extent that communal laundry facilities in multi-family houses, laundries in the quarter, or laundry services and refreshing cabinets in the home will actually save energy, financial incentive programmes and/or public investment for such infrastructures and services could be justified. In addition, public awareness, information, and motivation programmes for households to use these alternatives to an own washing machine could be essential to support them.

\section{Securing and creating the energy-sufficient infrastructure}

Households will only be able to perform some types of energy-sufficient practices, if the necessary infrastructure is available to them at all. Examples are places for hanging clothes to dry outside or in the loft or cool storage rooms that may partially substitute refrigerators. The legal requirements should be created in tenant or building (refurbishment) legislation to allow external drying and to at least safeguard existing drying or food storage rooms in residential buildings. New build of such rooms may not reduce the overall energy consumption, given the 'embodied energy' of the materials needed.

\section{General requirements}

Policies of all kinds need to be designed bearing in mind the risk of being unwittingly involved in 'constructing' or reproducing meanings of service and need. Such meanings are social, historical, and constantly changing. This should be taken into account in the selection of energy sufficiency actions targeted, as well as in policy design and implementation. 
A number of energy-sufficient practices may not need financial investment, but additional coordination efforts or time. This requires safeguarding sufficient time budgets and time windows for housework. It also creates the need for changes in the professional economy in order to take the care economy into account.

It is also important that energy sufficiency policy is designed and implemented in a way sensitive to the individual vulnerabilities and restrictions (e.g. financial shortages or lack of the necessary infrastructure) and particularly to the demands from caring and being cared for, as well as for the needs of those doing the caring or being cared for. This is equally relevant for the instruments on the micro- and meso-level discussed above as for the overarching instruments for limiting average dwelling floor area per person or electricity sales. Detail can be found in the criteria-based analysis of energysufficient practices (Thomas et al. 2015) and in Spitzner and Buchmüller (2016). A professional training corresponding to these sensitivity requirements for businesses, administrations, and policy and particularly for consultants is a necessity too.

In addition, both the care economy and energy sufficiency should be defined as tasks of consumer protection, along with the necessary rights and funding. This includes representation of the rights of households vis-avis the relevant infrastructure and service providers.

An integrated energy sufficiency and efficiency policy package for electricity use in the household

An integrated policy to advance energy sufficiency and efficiency needs to address the manifold preconditions, barriers, and situations faced by households and market actors, if it is to succeed. Figure 4 provides the overall picture of the micro- and meso-level approaches and instruments for supporting energy sufficiency that we analysed. On the one hand, they promote more energysufficient and energy-efficient practices and decisions for domains of needs and wants and the corresponding energy-related products (appliances, equipment) in an integrated way. On the other hand, they aim at limiting the increase in per-capita dwelling floor area, which has been an important driving factor increasing household energy consumption so far.

Both for domain/product and dwelling size policy, a combination of an instrument creating a binding overarching target with concrete instruments of financial

\title{
Instruments mitigating the macro drivers of energy consumption
}

\section{Instruments advancing energy sufficiency at the micro and meso level}

\author{
Products \\ Cap on electricity sales? \\ Or efficiency and sufficiency funds \\ Integrated domain/product policy \\ for energy efficiency and \\ energy sufficiency
}

Dwelling floor area

Cap on floor area per person:

Legally binding or policy target?

Instruments to support and inform

for new forms of housing, moving

to smaller dwellings, sharing flats

Fig. 4 Overview of approaches in the integrated energy sufficiency policy package to address residential sector electricity use; instruments with a question mark need further research 
incentives, advice, and regulation appears most promising and successful. For target setting, an electricity sales cap for suppliers (which could also be named an 'energy saving obligation scheme') - if the open issues we found for this instrument can be solved - or an energy efficiency and sufficiency fund can provide this function for the domains of needs and wants and the energyrelated products, while a cap could be put on average dwelling floor area too. The latter needs clarification of whether it could be legally binding or just serve as a policy target.

In addition, we found that there is the need to develop instruments that limit the macro drivers of energy consumption (cf. Thomas et al. 2015), but did not have the resources to analyse what these could be so far. Still, this category is included as a reminder in Fig. 4.

\section{Discussion}

As stated in the introduction, sufficiency has been discussed in the literature as either a status to be aimed for or as a field of concrete action. The work presented here analysed the latter, aiming to operationalise energy sufficiency actions - what does a change in the quantity and or quality of specific utility/service mean in concrete terms of routines, social practices, and preconditions in the environment of the household, the caregivers, and the individual? And what are the necessities and potential instruments for policy to support all those who are involved in implementing such actions, or even enable them?

Addressing these questions required a partly new set of methods for analysis of energy sufficiency actions and policies (cf. 'Methods, particularly for policy development' and Fig. 1). Implementing this set of methods enabled us first to identify a broad set of 125 types of potential energy sufficiency actions in the domains of needs and wants we analysed (steps 1 to 3, 'Defining the scope and potential actions: steps 1 to 3 of the domainlevel analysis'). However, there is no guarantee that we were able to identify all potential energy sufficiency actions in these domains - it is likely there will be more. Next, we were able to narrow these potential actions down to those that may be acceptable to households and particularly to caregivers, sometimes with the necessary preconditions in place, and are likely to have positive impacts on the natural environment (steps 4 and 5, 'Methods for analysis of what could be appropriate energy sufficiency policy packages: steps 4 to 7'). While we are confident that we identified most of the important barriers and preconditions in step 4, albeit with a likelihood there can be others, it proved quite difficult to judge the environmental sustainability particularly of actions on the substitution route. To give an example, will replacing the washing machine in each household by a refresher cabinet (reducing wash frequency) plus an external washing/cleaning service actually save energy, water, and other resources or environmental impacts, and if so, for all households or only under certain conditions? Answering these questions will usually require a thorough life-cycle analysis of alternative product-service systems, which was way beyond the capacity of this work.

In the final steps, we were able to identify which necessities and potential instruments and their packages there are for policy to support electricity sufficiency in household uses. However, how effective will these policies be in practice, and will they even be accepted in the respective political arenas? For instance, there would be the need to discuss the floor space policies we found useful with municipalities, as they would be the actors to implement most of them, and would be obligated parties under the cap on average dwelling floor area. Unfortunately, time and resources did not allow us to explore these policy concepts with municipalities. The same is true for many other policy instruments in the package we developed. Political resistance may, e.g., be expected from manufacturers, if the definition of the energy efficiency index of clothes washers, clothes driers, and dish washers is changed from $\mathrm{kWh} / \mathrm{kg}$ or $\mathrm{kWh} /$ setting to $\mathrm{kWh} /$ full load. We were only able to test the effectiveness and acceptance of some of the underlying options for energy sufficiency action in the survey with consumers.

Also, a full analysis of policies able to address the macro-level drivers of energy use or savings is still missing. As the aim of energy sufficiency is saving energy, one aspect related to macro drivers is can there be rebound effects for energy sufficiency? Literature discusses direct and indirect rebound effects (e.g. Gillingham et al. 2013). Direct rebound effects arise when technical energy saving potentials (mostly energy efficiency) are counterbalanced by behavioural changes/ shifts. As energy sufficiency actions involve little technical change, direct rebound effects are unlikely. On the contrary, energy sufficiency can be a means to limit direct rebounds that may result from energy efficiency, and thus energy sufficiency may help to exploit the full 
potentials of energy efficiency. However, there can also be effects of respending of energy costs saved or from macroeconomic/structural changes through relative price changes (indirect rebound effects). These may also arise through energy savings from energy sufficiency (Alcott 2008). Finally, where consumption levels are too low (insufficient), sufficiency may imply needs for additional consumption. All of this is a separate research field and not studied here.

Implementation of the dwelling floor area policies will also need to avoid increasing needs for transport that could arise if people move away from their work, social contacts, or the infrastructure they are used to. On the other hand, reducing average floor area per person compared to baseline trends would, overall, reduce the need for new build, which can be expected to mostly be located in suburbs or even more remote rural areas. Denser cities would thus need less transport.

Another important driver acting against energy sufficiency is economic growth: neither energy efficiency nor energy sufficiency alone or even in combination may be sufficient to deliver absolute energy savings, if growth rates are high, e.g. the 8 to $10 \%$ that were prevailing in China or other countries for some time. Notwithstanding rebound effects, if growth rates are more modest, e.g. 1 to $3 \%$, or even zero to negative, the combination of energy efficiency and energy sufficiency is much more likely to deliver absolute energy savings than either of them alone. Growth clearly is one of the macro drivers of energy consumption that was beyond the analysis in this paper.

\section{Conclusions and outlook}

What did we learn from our analysis of guiding principles, methodologies, concrete policies and measures, and a comprehensive policy package for electricity sufficiency in the residential sector? On the one hand, energy sufficiency actions and the policy support they need are more different from energy efficiency than we thought at the outset of the project work. Energy sufficiency actions will reduce utility aspects or change them qualitatively, and because of substitution options, the analytical approach cannot follow a single product type (as with efficiency) but has to follow rather a domain of needs and wants, often in the care economy. On the other hand, the resulting policy package for energy-related products looks quite similar overall to the well-known energy efficiency policy package. However, energy sufficiency policy has to deal with all the gendered aspects of the care economy and more generally with norms and social practices determining the demand for technical services, which are not as relevant for energy efficiency, because the latter does not imply a change in the demand for technical services. Taking these preconditions on board, it has been possible to advance the energy efficiency policy package for residential sector electricity uses to integrate energy sufficiency, and to develop a first set of policies for limiting the growth of average dwelling floor space.

As some services and practices that need to be developed as well as some instruments in the policy package are quite new, policy experimenting may be needed to create good practice case studies before broad implementation. Future work will need to test, evaluate, and refine the micro- and meso-level policies in this sense, but also to take a closer look at the macro drivers of energy demand, and how policy could contain them. After all, research on energy efficiency policy has a history of more than 40 years and still is far from being able to answer all questions. Nobody would expect one research project to be able to provide the full picture of an energy sufficiency policy and its potential impacts, benefits, and costs. A lot more research is needed in this relatively new field. The potential gains from an integrated energy efficiency and sufficiency policy provide motivation enough to explore its feasibility. If our estimate of the potential to reduce household energy consumption in Germany by $3 \%$ per year can be sustained by such policies, this will mean a total saving of about one third or $47 \mathrm{TWh} /$ year by 2030 . This would be equivalent to greenhouse gas emission reductions of $25 \mathrm{mn}$. tons per year (Thomas et al. 2017).

Acknowledgements We thank the members of the project's advisory board for fruitful discussion on the approach and results and six anonymous reviewers for their comments that helped us improve this paper.

Funding information This work received a financial support from the German Federal Ministry for Education and Research.

\section{Compliance with ethical standards}

Conflict of interest The authors declare that they have no conflict of interest. 
Open Access This article is distributed under the terms of the Creative Commons Attribution 4.0 International License (http:// creativecommons.org/licenses/by/4.0/), which permits unrestricted use, distribution, and reproduction in any medium, provided you give appropriate credit to the original author(s) and the source, provide a link to the Creative Commons license, and indicate if changes were made.

\section{References}

Alcott, B. (2008). The sufficiency strategy: would rich-world frugality lower environmental impact? Ecological Economics, 64(2008), 770-786.

Bachelet, M. (2011). Social protection floor for a fair and inclusive globalization. Report of the Social Protection Floor Advisory Group. ILO Reports. ILO International Labour Office. Geneva, ILO: 32.

Bertoldi, P. (2017). Are current policies promoting a change in behaviour, conservation and sufficiency? An analysis of existing policies and recommendations for new and effective policies. In ECEEE Summer Study proceedings (pp. 201211). Stockholm: ECEEE.

Bierwirth, A. and Thomas, S. (2015). Almost best friends: sufficiency and efficiency. Can sufficiency maximise efficiency gains in buildings? In: ECEEE 2015 Summer Study proceedings (pp. 71-82). Stockholm: ECEEE.

BMWi (2012): Germany's new energy policy. Heading towards 2050 with secure, affordable and environmentally sound energy. http://www.bmwi.de/English/Redaktion/Pdf/ germanys-new-energy-policy.

Brischke, L.-A., Lehmann, F., Leuser, L., Thomas, S., Baedeker, C. (2015). Energy sufficiency in private households enabled by adequate appliances, In: ECEEE 2015 Summer Study proceedings (pp. 1571-1582). Stockholm: ECEEE.

Brischke, L.-A., Leuser, L., Thomas, S., Thema, J., Kopatz, M., Spitzner, M., Baedeker, C., Lahusen, M., Ekardt, F., \& Beeh, M. (2016). Energiesuffizienz - Strategien und Instrumente für eine technische, systemische und kulturelle Transformation zur nachhaltigen Begrenzung des Energiebedarfs im Konsumfeld Bauen / Wohnen. Endbericht: Heidelberg: ifeu-Institut für Energie- und Umweltforschung Heidelberg.

Calwell, C. (2010). Is efficient sufficient? The case for shifting our emphasis in energy specifications to progressive efficiency and sufficiency. Stockholm: ECEEE.

Chesbrough, H. W. (2003). The new imperative for creating and profiting from technology. Harvard: Harvard Business Review Press.

Darby, S. (2007). Enough is as good as a feast-sufficiency as policy. In: ECEEE 2007 Summer Study proceedings (pp. 111-119). Stockholm: ECEEE.

Davis, A., Hirsch D., Padley M. and Marshall L. (2015). How much is enough? Reaching social consensus on minimum household needs. Loughborough: Centre for Research in Social Policy, Loughborough University.

Duscha, M. (2016). Gemeinschaftliches Wohnen in Heidelberg Kommunale Governance - Ansätze zur Förderung von Energiesuffizienz. Heidelberg: ifeu-Institut für Energie- und Umweltforschung Heidelberg.
Ecofys (2014). Evaluation of the energy labelling directive and aspects of the ecodesign directive. First findings and recommendations. http://www.energylabelevaluation. eu/tmce/First_findings_revised_7_February_2014.pdf.

Faiers, A., Cook, M., \& Neame, C. (2007). Towards a contemporary approach for understanding consumer behaviour in the context of domestic energy use. Energy Policy, 35(2007), $4381-4390$

Fasnacht, D. (2009). Open innovation in the financial services: growing through openness, flexibility, and customer integration. Berlin: Springer.

Fawcett, T., \& Parag, Y. (2014). Radical thinking: personal carbon trading. Australian Environment Review, 29(10), 304-308.

Fischer, C., Blanck, R., Brohmann, B.; Cludius, J., Förster, H., Heyen, D.A., Hünecke, K., Keimeyer, F., Kenkmann, T., Schleicher, T., Schumacher, K., Wolff, F., Beznoska, M. Steiner, V., Gruber, E., Holländer, E., Roser, A., SchakibEkbatan, K. (2016). Konzept zur absoluten Verminderung des Energiebedarfs: Potenziale, Rahmenbedingungen und Instrumente zur Erreichung der Energieverbrauchsziele des Energiekonzepts. Dessau-Roßlau, Freiburg, Berlin, Karlsruhe: Umweltbundesamt, Öko-Institut e.V., Freie Universität Berlin, IREES GmbH - Institut für Ressourceneffizienz und Energiestrategien.

Fraser, N. (2016). Contradictions of capital and care. In: New Left Review 100, July-August 2016. https://newleftreview. org/II/100/nancy-fraser-contradictions-of-capital-and-care (last call April 26th 2018).

Gillingham, K., Kotchen, M. J., Rapson, D. S., \& Wagner, G. (2013). Energy policy: the rebound effect is overplayed. Nature, 493(7433), 475-476.

Gottschlich, D.; Roth, S.; Röhr, U.; Hackfort, S.; Segebart, D.; König, C.; Härtel, A. (2014): Doing sustainable economy at the crossroads of gender, care and the green economy. Debates - Common Ground - Blind Spots. CaGE Texts 4/2014.

Intergovernmental Panel on Climate Change (IPCC) (2014). Climate change 2014 - synthesis report. https://www.ipcc. ch/pdf/assessment-report/ar5/syr/SYR_AR5_FINAL_full wcover.pdf (accessed 23 April 2018).

International Energy Agency (IEA) (2005). Evaluating energy efficiency policy measures \& DSM Programmes Volume I Evaluation Guidebook. Paris, France. www.bigee.net/s/1 nawwk.

International Energy Agency (IEA) (2014). Capturing the multiple benefits of energy efficiency. Paris, France: IEA.

International Energy Agency (IEA). (2016). Energy efficiency market report 2016. Paris: France.

Kaufmann, J. C. (1998). Dirty linen: couples and their laundry. London: Middlesex University Press.

Leuser, L., Lehmann, F., Duscha, M., Thema, J., \& Spitzner, M. (2016). Akzeptanz von Energiesuffizienzpraktiken im Haushalt. Auswertung einer quantitativen Breitenbefragung. Heidelberg: ifeu-Institut für Energie- und Umweltforschung Heidelberg.

Lorek, S., \& Fuchs, D. (2013). Strong sustainable consumption governance - precondition for a degrowth path? Journal of Cleaner Production, 38(2013), 36-43.

Matthes, F., Busche, J., Döring, U., Emele, L., Gores, S., Harthan, R., Hermann, H., Jörß, W., Loreck, C., Scheffler, M., Hansen, P., Dieckmann, J., Horn, M., Eichhammer, W., Elsland, R., 
Fleiter, T., Schade, W., Schlomann, B., Sensfuß, F., \& Ziesing, H.-J. (2013). Politikszenarien für Klimaschutz, VITreibhausgas-Emissionsszenarien bis zum Jahr 2030. Dessau: Umweltbundesamt.

Munkacsi, N., Mahapatra, K. (2017). The role of social influence in the end customer purchasing decisions on the heat market. In: ECEEE 2017 summer study proceedings (pp. 21052110). Stockholm: ECEEE.

Pfäffli, K. (2012). Grundlagen zu einem Suffizienzpfad Energie. Das Beispiel Wohnen. Zurich: Stadt Zürich - Amt für Hochbauten.

Princen, T. (2005). The logic of sufficiency. Cambridge: MIT Press.

Reichwald, R., Meyer, A., Engelmann, M., \& Walcher, D. (2007). Der Kunde als Innovationspartner: Konsumenten integrieren, Flop-Raten reduzieren, Angebote verbessern. Berlin: Springer.

Rockström, J., Steffen, W., Noone, K., Persson, Å., Chapin, F. S., Lambin, E. F., Lenton, T. M., Scheffer, M., Folke, C., Schellnhuber, H. J., Nykvist, B., de Wit, C. A., Hughes, T., van der Leeuw, S., Rodhe, H., Sörlin, S., Snyder, P. K., Costanza, R., Svedin, U., Falkenmark, M., Karlberg, L., Corell, R. W., Fabry, V. J., Hansen, J., Walker, B., Liverman, D., Richardson, K., Crutzen, P., \& Foley, J. A. (2009). A safe operating space for humanity. Nature, 461(7263), 472-475. https://doi.org/10.1038/461472a.

Rosenow, J., Fawcett, T., Eyre, N., \& Oikonomou, V. (2016). Energy efficiency and the policy mix. Building Research \& Information, 44(2016), 562-574.

Sachs, W. (1993). Die vier E's: Merkposten für einen maßvollen Wirtschaftsstil. In: Politische Ökologie. Heft 33 (1993), pp. 69-72.

Sachverständigenrat der Bundesregierung für Umweltfragen (SRU) (2011). Wege zur $100 \%$ erneuerbaren Stromversorgung. Sondergutachten. http://www.umweltrat. $\mathrm{d}$ e / S h a r e d D o c s / D o w n 1 o a d s / D E / 02 Sondergutachten/2011_07_SG_Wege_zur_100_Prozent_ erneuerbaren_Stromversorgung.pdf? blob=publicationFile.

Schneidewind, U., Zahrnt, A. (2014). The politics of sufficiency: making it easier to live the good life. https://epub.wupperinst. org/frontdoor/index/index/docId/5550.

Schultz, I, (1993). Der GlobalHaushalt - der "Naturhaushalt" und die ökologische Verantwortung der Frauen. In: Schultz, I. (Ed.): GlobalHaushalt: Globalisierung von Stoffströmen Feminisierung von Verantwortung. Dokumentation einer Veranstaltung des Instituts für sozial-ökologische Forschung (ISOE). Forschungstexte d. Inst. f. sozial-ökol. Forschung Bd. 3. Frankfurt a.M.: IKO-Verl. f. Interkulturelle Kommunikation. ISBN 3-88939-253-9, S. 11-24.

Schultz, I. (1996). Von der Liebe der Männer zu nachhaltigen Zahlen. In: Ministerium für Umwelt, Raumordnung und Landwirtschaft des Landes Nordrhein-Westfalen (MURL) (Ed.) (1997): Nachhaltigkeit und Zukunftsfähigkeit aus Frauensicht. Düsseldorf.

Schultz, I. (1998): Umwelt- und Geschlechterforschung - eine notwendige Allianz. ISOE-DiskussionsPapiere, 2. Frankfurt am Main: ISOE - Institute for Social-Ecological Research. http://www.cage-online.de/wp-content/uploads/2015/02 /CaGE_Texte_4-2014_engl.pdf.

Shove, E. (2003). Comfort, cleanliness and convenience: the social organization of normality. Oxford: Berg.
Shove, E. (2017). What is wrong with energy efficiency? Building Research \& Information, 46, 779-789. https://doi. org/10.1080/09613218.2017.1361746.

Skidelsky, R., \& Skidelsky, E. (2013). Wie viel ist genug? Vom Wachstumswahn zu einer Ökonomie des guten Lebens. München: Kunstmann.

Spengler, L. (2018). Sufficiency as policy. Baden-Baden: Nomos.

Spitzner, M. (1999): Krise der Reproduktionsarbeit Kerndimension der Herausforderungen eines öko-sozialen Strukturwandels. Ein feministisch-ökologischer Theorieansatz aus dem Handlungsfeld Mobilität. -.- In: Hoffmann, E., Hofmeister, S., Weller, I. (Ed.) (1999): Nachhaltigkeit und Feminismus: Neue Perspektiven - Alte Blockaden (Sustainability and Feminism: new Perspectives - old Barriers). Bielefeld: Kleine Verlag, 151-165.

Spitzner, M, Beik, U. (1995). Reproduktionsarbeits-Mobilität. Theoretische und empirische Erfassung, Dynamik ihrer Entwicklung und Analyse ökologischer Dimensionen und Handlungsstrategien. In: Spitzner, M., Hesse, M., Holzapfel, H. (Ed.) (1999): Entwicklung der Arbeits- und Freizeitmobilität - Rahmenbedingungen von Mobilität in Stadtregionen. Forschungsberichte des vom Bundesministeriums für Bildung, Wissenschaft, Forschung und Technologie geförderten Verbundforschungprojekts, Bd.5. Wuppertal: Forschungsverbund Ökologisch verträgliche Mobilität.

Spitzner, M., Buchmüller, S. (2016). Energiesuffizienz Transformation von Energiebedarf, Versorgungsökonomie, Geschlechterverhältnissen und Suffizienz. Bericht zum emanzipativen Suffizienzansatz, zur neuen genderreflektierten Methodik und Auswertung einer Fokusgruppe (Wuppertal Report 8). ISSN 18621953.Wuppertal: Wuppertal Institut für Klima, Umwelt, Energie gGmbH.

Thema, J. (2015). Kriteriengestützte Analyse von Optionen energiesuffizienten Handels im Sektor Bauen/Wohnen. Wuppertal: Wuppertal Institut für Klima, Umwelt, Energie $\mathrm{gGmbH}$.

Thema, J., Thomas, S., Kopatz, M., Spitzner, M., \& Ekardt, F. (2016). Energiesuffizienzpolitik mit Schwerpunkt auf dem Stromverbrauch der Haushalte. Wuppertal: Wuppertal Institut für Klima, Umwelt, Energie gGmbH.

Thomas, S., Aydin, V., Kiyar, D., Tholen, L., Venjakob, M. (2013). Strategic policy packages to deliver energy efficiency in buildings - their international evidence. In: ECEEE 2013 Summer Study proceedings (pp. 1399-1410). Stockholm: ECEEE.

Thomas, S., Hennicke, P., Bierwirth, A., Venjakob, M., Hauptstock, D., Kiyar, D., Suerkemper, F., Thema, J., Tholen, L., \& Vondung, F. (2013b). Vorschlag für eine Bundesagentur für Energieeffizienz und einen Energiesparfonds (BAEff). Wuppertal: Wuppertal Institut.

Thomas, S., Brischke, L.-A., Thema, J., Kopatz, M. (2015). Energy sufficiency policy: an evolution of energy efficiency policy or radically new approaches? In: ECEEE 2015 Summer Study proceedings (pp. 59-70). Stockholm: ECEEE.

Thomas, S., Thema, J., \& Kopatz, M. (2017). Ansätze für eine Energiesuffizienzpolitik. Energiewirtschaftliche Tagesfragen, 67 (2017), 7, 59-62.

Toulouse, E., Le Du, M., Gorge, H., Semal, L. (2017). Stimulating energy sufficiency: Barriers and opportunities. In: ECEEE 
2017 Summer Study proceedings (pp. 59-68). Stockholm: ECEEE.

Tronto, J. C. (2013). Caring democracy. Markets, equality, and justice. New York: New York University Press ISBN 978-08147-8278-1.

UBA - German Environment Agency (Ed.) (2018). Gendergerechtigkeit als Beitrag zu einer erfolgreichen Klimapolitik - Forschungsreview, Analyse internationaler Vereinbarungen, Portfolioanalyse. Elaborated by Röhr, U.; Alber; G.; Göldner, L. UBA-Texte 23/2018. Berlin/ Dessau: UBA.

Von Hippel, E. (1986). Lead users: an important source of novel product concepts. Management Science, 32, 791-805.

von Werlhof, C. (1978). Frauenarbeit: Der blinde Fleck in der Kritik der politischen Ökonomie. In: Beiträge zur Feministischen Theorie und Praxis, 1 (1978), pp. $18 f f$. München: Verlag Frauenoffensive.

von Winterfeld, U. (2011). Niemand soll immer mehr haben wollen müssen - Vom Recht auf Suffizienz. FrauenRat, 5(2011), 13-16.
Walcher, D. (2009). Der Ideenwettbewerb als Methode der Open Innovation. In: Kommunikation als Erfolgsfaktor im Innovationsmanagement, pp. 141-157. Berlin: Springer.

Wichterich, C. (2018). Der prekäre Care-Kapitalismus. In: Blätter für deutsche und internationale Politik, 2/18 (2018), 91-99.

Wilhite, H. (2016). The political economy of low carbon transformation: breaking the habits of capitalism. Abingdon, Oxfordshire: Routledge.

Wilhite, H. and Lutzenhiser, L. (1997). Social loading and sustainable consumption. Proceedings of the European Council for an Energy Efficient Economy, Summer Study 1997, France.

Wilhite, H. and Norgard, J. S. (2003). A case for self-deception in energy policy. Proceedings of the ECEEE summer study 2003.

Wilk, R. (2002). Consumption, human needs, and global environmental change. Global Environmental Change, 12(2002), 513.

Zhao, L., \& Deek, F. P. (2004). User collaboration in open source software development. Electronic Markets, 14, 89-103. 